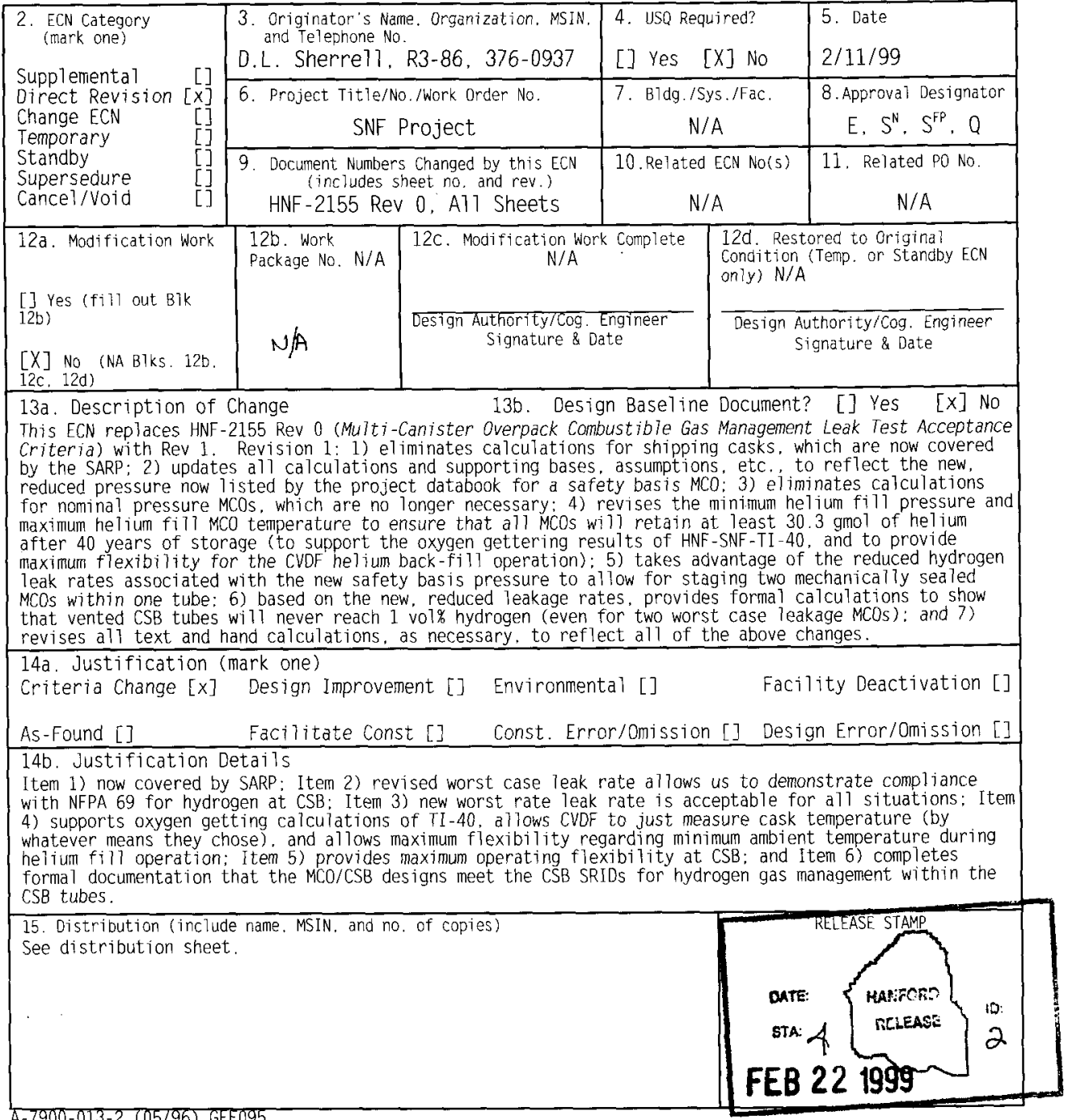




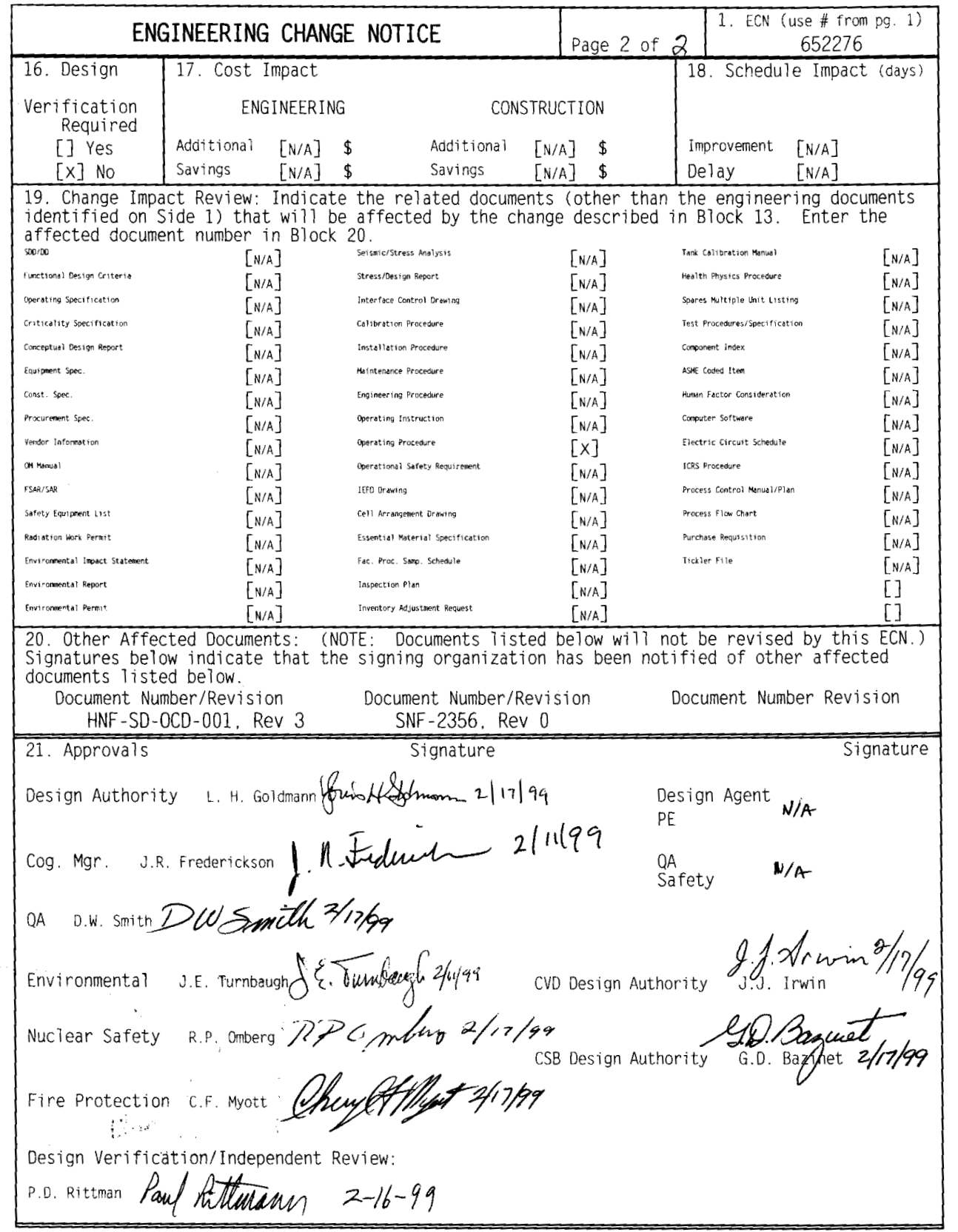


HNF - 2155, Rev. 1

\section{MCO Combustible Gas Management Leak Test Acceptance Criteria}

D. L. Sherret1

DE\&S Hanford. Inc., Richland. WA 99352

U.S. Department of Energy Contract DE-AC06-96RL13200

EDT/ECN: 652276

UC: 510

Org Code: 2F300

Charge Code: 105355/BA040

B\&R Code: EW7040000

Total Pages: 62

Key Words: Spent Nuclear Fuel Project. Multi-canister Overpack. Mco, leak test criteria, ANSI N14.5. Canister Storage Building, CSB, helium backfill, helium loss, hydrogen leakage, stagnant air. National Fire Protection Association. NFPA 69. Lower Flammable Limit, LFL

Abstract: Existing leak test acceptance criteria for mechanically sealed and weld sealed multi-canister overpacks (MCO) were evaluated to ensure that Mcos can be handled and stored in stagnant air without compromising the Spent

Nuclear Fuel Project's overall strategy to prevent accumulation of combustible gas mixtures within MCO's or within their surroundings. The document concludes that the integrated leak test acceptance criteria for mechanically sealed and weld sealed MCOs ( $1 \times 10^{-5} \mathrm{std} \mathrm{cc} / \mathrm{sec}$ and $1 \times 10^{-7} \mathrm{std} \mathrm{cc} / \mathrm{sec}$. respectively) are adequate to meet al 1 current and foreseeable needs of the project, including capability to demonstrate compliance with the NFPA 69 Paragraph 3-3

requirement to maintain hydrogen concentrations [within the air atmosphere CSB tubes] at or below 1 vol\% (i.e., at or below $25 \%$ of the LFL).

TRADEMARK DISCLAIMER. Reference herein to any specific commercial product, process, or service by trade name, trademark, manufactumer, or otherwise. does not necessarily constitute or imply its endorsement, recormendation, or favoring by the United States Government or anly agency thereof or its contractors or subcontractors.

Printed in the United States of America. To obtain copies of this document, contact: Document Control Services, P. 0. Box 950. Mailstop H6-08. Richland WA 99352, Phone (509) 372-2420; Fax (509) 376-4989
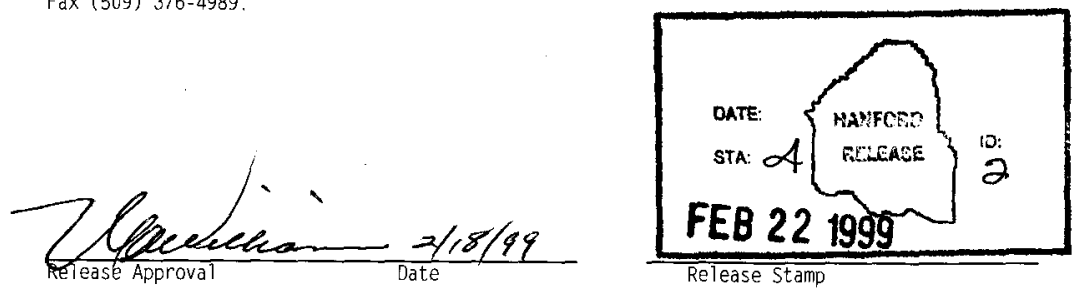

Release Stamp

\section{Approved for Public Release}




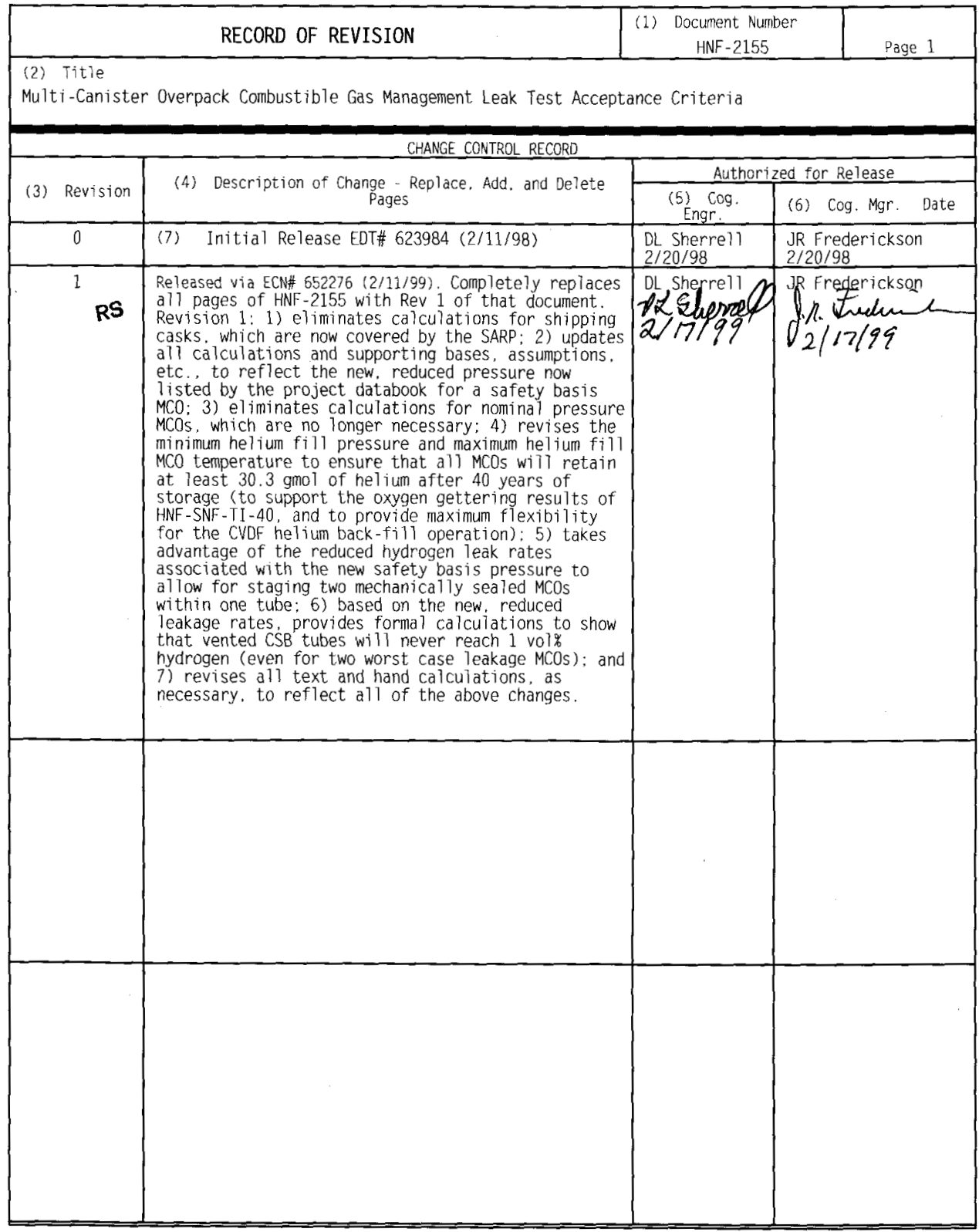


HNF-2155 Rev 1

MULTI-CANISTER OVERPACK COMBUSTIBLE GAS MANAGEMENT LEAK TEST ACCEPTANCE CRITERIA 


\section{MULTI - CANISTER OVERPACK COMBUSTIBLE GAS MANAGEMENT LEAK TEST ACCEPTANCE CRITERIA TABLE OF CONTENTS}

1.0 PURPOSE

1.1 SCOPE
1.1 .1
1.1 .2
1.1 .3

Loss of Hydrogen From CSB Tubes via Tube Vents

Replacement of Backfill Gas At CSB

Hydrogen Release to MCO/Cask Assembly During

Transport Operations

2.0 SUMMARY OF RESULTS AND CONCLUSIONS

2.1 RECOMMENDATIONS

2.1.1 Recommendations For MCOS With Mechanical Seals

2.1.2 Recommendations For MCOs With Welded End Closures

2.2 RESULTS AND CONCLUSIONS FOR MECHANICALLY SEALED MCOS

2.2.1 Helium Retention

2.2.2 Hydrogen In CSB Tubes

2.3 RESULTS AND CONCLUSIONS FOR WELD SEALED MCOS ....... . 3

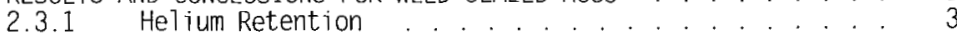

2.3.2 Hydrogen In CSB Tubes..... 4

2.4 NATIONAL FIRE PROTECTION ASSOCIATION COMPLIANCE . . . . . . . 4

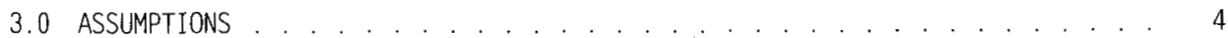

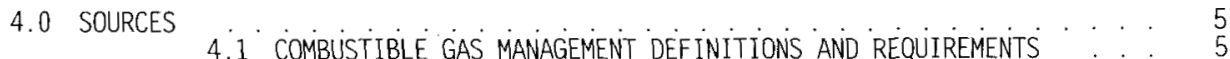

4.2 LEAK RATE DEFINITIONS AND LEAK RATE CORRELATION EQUATIONS : . 5

4.3 MCO GAS INVENTORIES 5

4.4 MCO BACKFILL TEMPERATURE AND MCOICSB TUBË OPERATING TEMPERATURES

4.5 GAS PROPERTY DATA

4.6 BAROMETRIC DATA

4.7 CSB STORAGE TUBE VOID VOLUMES

5.0 COMBUSTIBLE GAS MANAGEMENT FUNCTIONS AND REQUIREMENTS $\ldots \ldots \ldots$

5.1 FUNCTION: PRECLUDE COMBUSTIBLE MIXTURES INSIDE MCOS $\cdots$

5.1.1 Functional Requirement: Prec7ude Air Ingress to MCOS

5.1.1.1 Implementation Criteria 8

5.1.1.1.1 Minimum Time To Maintain Positive Pressure 9

5.1.1.1.2 Type of Backfil1 Gas .......... 10

5.1.1.1.3 Maximum Backfi17 Pressure . . . . . . . . 10

5.1.1.1.4 Minimum Backfjll Pressure . . . . . 10

5.1.2 NFPA 69 Paragraph 2-7.2 Compliance Status . . 11

5.1.2.1 Non-Compliance with Specific Requirements . . . 11

5.1.2.2 NFPA 69 Paragraph 2-7.2 Equivalency. . . . . 12

5.1.2.2.1 Strategy To Achieve NFPA 69

Paragraph 2-7.2 Equivalency 
5.2 FUNCTION: PRECLUDE COMBUSTIBLE MIXTURES OUTSIDE MCOS .... 13 5.2.1 Functional Requirement: Limit $\mathrm{H}_{2}$ Release From MCOS . . 14

5.2.1.1 Implementation Criteria . . . . . . . 14

5.2.1.1.1 Acceptable $\mathrm{H}_{2}$ Concentration ..... . 14

5.2.1.1.2 Minimum Time To Maintain Acceptable $\mathrm{H}_{2}$
Concentration. . 14

5.2.2 NFPA 69 Paragraph $3-3$ Compliance Status . . . . 14

6.0 PREDICTION OF OPERATIONAL LEAKAGE FROM LEAK TEST RESULTS . . . . . . . 15

6.1 LEAKAGE CORRELATION OEF INITIONS AND METHODOLOGY $\ldots . . .15$

6.1.1 Shortcomings of The ANSI N14.5-1987 Approach . . . 16

6.1.2 The Revised Approach In ANSI N14.5-1997 Draft J . . 17

7.0 CALCULATIONS

7.1 MCO OPERATING CONDITIONS $\quad \cdots$

7.1 .1 MCO Gas Temperatures $\ldots . .7 .78$

7.1.2 MCO Gas Inventories ......... 18

7.1.2.1 Worst Case Gas Inventory For Calculating . . . 18
HeTium Loss. 18

7.1.2.1.1 Minimum Initiai Backfili Gás Quantity : 18

7.1.2.1.2 Minimum Required MCO Helium Inventory : 19

7.1.2.1.3 Maximum Acceptable Helium Loss ... . . . 20

7.1.2.1.4 Design Goal for Maximum Helium Loss . . 20

7.1.2.2 Worst Case Gas Inventory For Calculating Hydrogen Release ............... 21

7.1.3 Mco Operating Pressures
7.1.3.1 Maximum Pressure For Helium Loss Calculations :

7.1.3.2 Maximum Pressure For Hydrogen Release Calculations . . . . . . . 21

7.2 DOCUMENTATION/VALIDATION OF FLOW CORRELATION CALCULATIONS . . 21

7.2.1 ANSI N-14.5 Draft 1997 J Equations and Guidelines . . 21

7.2.1.1 Definition of Symbols ............ 22

7.2 .1 .2 Basic flow Equations $\ldots . .23$

7.2.1.3 Hand Calculation At Reference Conditions . . . 23

7.2.1.4 Hand Carculation At Test Conditions..... 24

7.2.1.5 Hand Calculation At Operating Conditions... . 26

7.2.1.5.1 Helium Loss Calculations . . . . . . . . . 26

7.2.1.5.2 Hydrogen Release Calculations . . 28

7.3 MAXIMUM STEADY STATE HYOROGEN CONCENTRATION IN CSB TUBES : . . 31

7.3.1 Dilution by Barometrically Induced Breathing . . . . 31

7.3.1.1 Assumptions .................... 31

7.3.1.2 Basis For Air-Exchange Rate ......... . 31

7.3.1.3 Material Balance Equations . . . . . . . 32

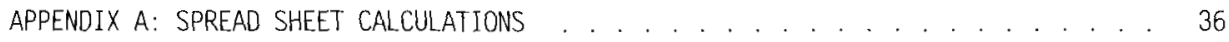

APPENDIX B: THE NFPA 69 EXPLOSION PREVENTION STANDARD ............ 40

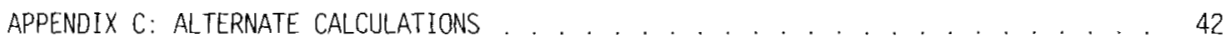

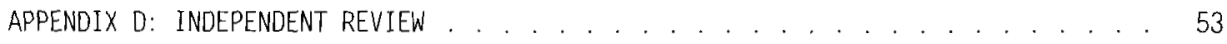

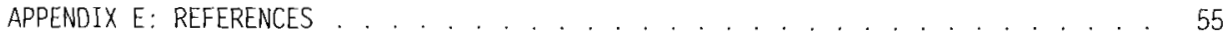




\section{ACRONYMS/ABBREVIATIONS}

$\begin{array}{ll}\text { CSB } & \text { Canister Storage Building } \\ \text { CVDF } & \text { Cold Vacuum Drying Facility } \\ \text { DOE } & \text { U.S. Department of Energy } \\ \text { LOC } & \text { Limiting Oxidant Concentration } \\ \text { LFL } & \text { Lower Flammable Limit } \\ \text { MCO } & \text { multi-canister overpack } \\ \text { MHM } & \text { MCO Handling Machine } \\ \text { NFPA } & \text { National Fire Protection Association } \\ \text { pSia } & \text { absolute pressure, pounds per square inch } \\ \text { PSig } & \text { gage pressure, pounds per square inch } \\ \text { SNF } & \text { Spent Nuclear Fuel }\end{array}$




\section{EXECUTIVE SUMMARY}

Leak test acceptance criteria for mechanically sealed and weld sealed multi-canister overpacks (MCO) were evaluated to ensure that, in the uni ikely event the leak test results for an MCO were to approach either of those criteria, it could still be handled and stored in stagnant air without compromising the Spent Nuclear Fuel Project's overa 17 strategy to prevent accumulation of combustible gas mixtures within MCOS or within their surroundings. Note: with the exception of the mechanical seal's leak test acceptance criterion itself (which is evaluated by this document), this document does not apply to MCOs unti1 they have been completely processed and acceptance tested at the Cold Vacuum Drying Facility (CVDF). Also note that this document doesn't address release of radiological contamination from MCOs.

\section{Recommendations for Mechanically Sea Ted MCOS}

The integrated leak test acceptance criterion for mechanically sealed McOs should remain at $1 \times 10^{-5} \mathrm{std} \mathrm{cc} / \mathrm{sec}$. This will ensure:

1) that a positive helium gage pressure would remain within any mechanically sealed MCO for well over 40 years without replenishment:

2) that it would take over 3 years for the hydrogen concentration to reach 1 vol\% within a sealed (no allowance for loss via the tube's vent port) singly occupied storage tube containing a safety basis pressure MCO with mechanical seals (note that the particular combination of gas inventory and temperature required to produce the pressure used for this leakage calculation is not expected to occur for any MCO during the first few years of storage, nor for the majority of MCOs during up to 40 years of storage);

3) that it would take over ten months for the hydrogen concentration to reach 1 vol\% within a sealed storage tube containing two safety basis pressure MCOs with mechanical seais;

4) that, based on barometrically induced air exchange alone (i.e., no credit is taken for volume expansion from thermal cycling or for diffusion), a vented CSB tube containing the worst case MCO payload for hydrogen leakage (2 each, mechanically sealed. safety basis pressure MCOS) wi 11 never exceed 1 vol\% hydrogen (see section 7.3 ); and

5) that, based on diffusion alone (i.e., no credit is taken for barometrically induced air exchange or thermal cycling), a vented CSB tube containing the worst case MCO payload for hydrogen leakage ( 2 each. mechanically sealed, safety basis pressure MCOs) will never exceed 1 vol\% hydrogen (see Appendix C).

\section{Recommendations for Weld Sealed MCOs}

The existing $1 \times 10^{-7} \mathrm{std} \mathrm{cc} / \mathrm{sec}$ leak test acceptance criterion for $\mathrm{MCO}$ welds was determined to be adequate to meet a 11 current and foreseeable needs of the project. 


\subsection{PURPOSE}

The purpose of this document is to support the Spent Nuclear Fue? Project's combustible gas management strategy while, at the same time, avoiding the need to impose any requirements for oxygen free atmospheres within storage tubes that contain multi-canister overpacks (MCO). In order to avoid inerting requirements it is necessary to establish and confirm leak test acceptance criteria for mechanically sealed and weld sealed Mcos that are adequate to ensure that, in the unlikely event the leak test results for any MCO were to approach either of those criteria, it could still be handled and stored in stagnant air without compromising the SNF Project's overall strategy to prevent accumulation of combustible gas mixtures within Mcos or within their surroundings. To implement that strategy, this document: 1) establishes combustible gas management functions and minimum functional requirements for the MCO's mechanical seals and closure weld(s); 2) establishes a maximum practical value for the minimum required initial MCO inert backfill gas pressure; and 3) based on items 1 and 2, establishes and confirms leak test acceptance criteria for the MCO's mechanical seal and final closure weld(s).

\subsection{SCOPE}

The overall scope of this document is limited to consideration of leak testing criteria that pertain directly to the above stated purpose(s). Ihis document does not address release of radiological contamination from MCOs (i.e., it does not address the implications of a given leak test acceptance criterion with respect to the MCO's radiological confinement function).

The scope is further limited to evaluation of gas leakage: 1) from mechanically sealed, pressurized MCOs that have successfully undergone leak testing at the cold vacuum Drying Facility (CVDF) following completion of the CVDF process: and 2) from pressurized MCOs that have successfulty undergone leak testing following completion of their final closure weld(s) at the Canister Storage Building (CSB). Any evaluation of MCO gas Teakage prior to completion of the CVDF process is beyond the scope of this document.

\subsubsection{Loss of Hydrogen From CSB Tubes via Tube Vents}

Whereas Revision 0 of this document did not quantitatively address (nor take credit for) loss of hydrogen from tubes via the stagnant tube vents, section 7.3 of this revision (Revision 1) provides calculations to confirm that no vented CSB tube, regardless of its payload configuration. will ever exceed 1 vol\% hydrogen. An alternate calculation has also been added (see Appendi $x$ C) to further substantiate the conclusions of section 7.3 .

\subsubsection{Replacement of Backfill Gas At CSB}

This document does not address replacement of backfill gas for MCOs that are sampled at the CSB. 


\subsubsection{Hydrogen Release to MCO/Cask Assembly During Transport Operations}

As of Revision 1, this document no longer addresses hydrogen release from MCOs into the MCO transportation cask. Those calculations are now provided by the Safety Analysis Report for Packaging (Onsite) Multi-canister Overpack (HNF-SD-TP-SARP-017).

\subsection{SUMMARY OF RESULTS AND CONCLUSIONS}

\subsection{RECOMMENDATIONS}

The following recommendations are based on functions and requirements developed in section 4.0 .

\subsubsection{Recommendations For MCOs With Mechanical Seals}

The integrated leak test acceptance criterion for mechanicaliy sealed MCOs should continue to be specified as $1 \times 10^{-5} \mathrm{std} \mathrm{cc} / \mathrm{sec}$. The above leak test acceptance criterion is reasonable in light of the Test Report For Multiple Canister Overpack Mechanical Closure Prototype Testing (WHC-SD-SNFTRP-018). The last paragraph of section 3.2 in that report states that the prototype mechanical seal "... had a leak rate of $1.4 \times 10^{-7} \mathrm{std}-\mathrm{cc} / \mathrm{s} \ldots$.." at the $M C O^{\circ} S 132^{\circ} \mathrm{C}$ maximum design temperature for CSB storage operations.

\subsubsection{Recommendations For MCOs With Welded End Closures}

The current integrated leak test acceptance criterion for MCOs with weided end closures $\left(1 \times 10^{-7} \mathrm{std} \mathrm{cc} / \mathrm{sec}\right)$ should be retained. This criterion is reasonable for a welded closure and is more than adequate to meet a17 the functional requirements that are imposed in section 5.0 . It is also adequate to accommodate any foreseeable changes to the functional requirements that might be expected to occur as the project evolves.

\subsection{RESULTS AND CONCLUSIONS FOR MECHANICALLY SEALED MCOS}

\subsubsection{Helium Retention}

The recommended leak test acceptance criterion for the MCO's mechanically sealed end closure $\left(1 \times 10^{-5} \mathrm{std} \mathrm{cc} / \mathrm{sec}\right)$ wi 17 ensure a positive helium gage pressure within both nominal and safety basis pressure MCOs for over 76 years. It wi 17 also ensure retention of the 30.3 gmol minimum helium inventory used to calculate safety basis oxygen concentrations (see section 5.1.1.1.4) for over 40 years. This will provide an adequate design margin to accommodate any changes to requirements that may occur as the project evolves. 
HNF-2155 Rev 1

\subsubsection{Hydrogen In CSB Tubes}

\section{Hydrogen Within Singly Occupied, Un-Vented CSB Tubes}

The current leak test acceptance criterion for the MCO's mechanicaliy sealed end closure $\left(1 \times 10^{-5}\right.$ std $\left.\mathrm{cc} / \mathrm{sec}\right)$ will ensure that it would take over 3 years for the hydrogen concentration to reach 1 vol\% (25\% of its Lower Flammable Limit -- LFL) within an un-vented, singly occupied storage tube containing a safety basis pressure case $\mathrm{MCO}$ with mechanical seals. Note that the particular combination of gas inventory and temperature required to produce the pressure used for this leakage calculation is not expected to occur for any MCO during the first few years of storage, nor for the majority of MCOs during up to 40 years of storage.

Hydrogen Within Doubly Occupied, Un-vented CSB Tubes

The current leak test acceptance criterion for the MCO's mechanically sealed end closure $\left(1 \times 10^{-5}\right.$ std $\left.\mathrm{cc} / \mathrm{sec}\right)$ will ensure that it would take over ten months for the hydrogen concentration to reach 1 vol\% within an un-vented storage tube containing two safety basis pressure MCOs with mechanical seals.

\section{Hydrogen Within Vented CSB Tubes}

Based on dilution of hydrogen via the air exchange that accrues from barometric pressure variations alone (i.e., with no additional allowance for thermal cycling or diffusion), the current leak test acceptance criterion for the MCO's mechanically sealed end closure $\left(1 \times 10^{-5} \mathrm{std} \mathrm{cc} / \mathrm{sec}\right)$ will ensure that no vented CSB tube wi11 ever exceed 1 vo $1 \%$ hydrogen, even if it contains two safety basis pressure MCOs with mechanical seals (see section 7.3).

Appendix $C$ provides an alternate calculation that reaches the same conclusion. based on static diffusion alone, with no allowance for air exchange from barometric or thermal cycling. In view of the fact that both mechanisms (mass flow and static diffusion) will actually be active at the same time. the overa 17 conclusion is that no vented CSB tube wil1 ever reach 1 vol\% hydrogen unless it contains an MCO with a defective seal or breached wa11, etc.

\subsection{RESULTS AND CONCLUSIONS FOR WELD SEALED MCOS}

\subsubsection{Helium Retention}

The existing leak test acceptance criterion for the welded MCO closure $\left(1 \times 10^{-7} \mathrm{std} \mathrm{cc} / \mathrm{sec}\right)$ is more than adequate to retain a positive helium gage pressure within safety basis pressure case MCOs for thousands of years. This means that any MCO could contain dozens of individually tested welds (as opposed to a single integrated leak test to confirm $\leq 1 \times 10^{-7} \mathrm{std}(\mathrm{cc} / \mathrm{sec}$ ) and still retain a positive helium gage pressure well beyond the project life. The $1 \times 10^{-7} \mathrm{std} \mathrm{cc} / \mathrm{sec}$ criterion will also ensure retention of the $30.3 \mathrm{gmo}$ minimum helium inventory used to calculate oxygen concentrations (see section 5.1.1.1.4) over the entire project 7 ife. This statement would be valid, even if an MCO contained more than seven individually tested welds that almost failed to meet the leak test specification. 


\section{HNF-2155 Rev 1}

\subsubsection{Hydrogen In CSB Tubes}

Hydrogen in Un-Vented CSB Tubes

The existing $1 \times 10^{-7} \mathrm{std} \mathrm{cc} / \mathrm{sec}$ leak test acceptance criterion for MCO welds is adequate to maintain the hydrogen concentration below 1 vol\% for over 100 years within a completely sealed storage tube containing two safety basis pressure MCOs. each of which almost failed the leak test.

Hydrogen In Vented Storage Tubes

Based on dilution of hydrogen within vented CSB tubes by air exchange that accrues from barometric pressure variations alone (i.e., with no additional allowance for thermal cycling or diffusion), the current leak test acceptance criterion for MCO welds $\left(1 \times 10^{-7} \mathrm{std} \mathrm{cc} / \mathrm{sec}\right)$ wi 71 ensure that no vented CSB tube wi 17 ever reach 1 vol\% hydrogen (see section 7.3 ).

\subsection{NATIONAL FIRE PROTECTION ASSOCIATION COMPLIANCE}

Appendix B provides a summary of the National Fire Protection Association (NFPA) Standard on Explosion Prevention Systems (NFPA 69), along with a general discussion of its application to the MCO. Section 5.2.2 of this document describes the project's status with respect to Paragraph 3-3 of NFPA 69 and concludes, based on the hydrogen leakage calculation results of section 7.2 (summarized on the third sheet of Appendix A) and the subsequent atmospheric air exchange calculations of section 7.3 (and Appendix $C$ ), that a11 MCO handling, staging, and storage operations currently envisioned for the CSB can be performed in compliance with the requirements of NFPA 69 Paragraph 3-3. See section 5.2.1 for a description of the project's status with respect to NFPA 69 Paragraph 2-7.2, which applies to conditions within MCOs.

\subsection{ASSUMPTIONS}

A17 assumptions are identified and justified as they are applied. 


\subsection{SOURCES}

\subsection{COMBUSTIBLE GAS MANAGEMENT DEFINITIONS AND REQUIREMENTS}

Section 12.1.1 (Fire Protection. Management, Program Policy) of the CSB's Standards/Requirements Identification Document (HNF-SD-SNF-RD-007) invokes a 1 applicable NFPA codes and standards, listing the requirement source as paragraph 5.C of D0E 5480.7A (Fire Protection). Because MCOs are expected to contain hydrogen gas, the overall process design (including, but not limited to, the design of the MCO itself) is required to comply with all applicable sections of NFPA 69 (Standard on Explosion Prevention Systems). See Appendix $B$ of this document for a summary description of NFPA 69, along with a genera? discussion of its application to the MCO.

Additional requirements for evaluation of bounding case MCOs are taken from NRC Regulatory Guide 1.7 (Control of Combustible Gas Concentrations in Containment following a Loss-of-Coolant Accident).

\subsection{LEAK RATE DEFINITIONS AND LEAK RATE CORRELATION EQUATIONS}

Section 4.13 of the current MCO performance specification (HNF-S-0426) requires a 17 MCO seals to be ".. leakage rate testable in accordance with ANSI N14.5...." Therefore a11 leak rate definitions and leak rate correlation equations used in this document are taken from the American National Standard For Radioactive Materials -- leakage tests on packages for shipment (ANSI N14.5). See section 6.1, below, for additional detai1.

\subsection{MCO GAS INVENTORIES}

Table 4-1 of the Spent Nuclear Fuel Product Specification (HNF-SD-SNFOCD-001) 7ists the maximum backfill gas inventory of an MCO as 41.3 gmol. based on a $500 \mathrm{~L}$ minimum $M C O$ void volume that has been backfilled to a maximum pressure of $12.5 \mathrm{psig}$ (27.2 psia -. $1.85 \mathrm{~atm}$ ) at a minimum MCO/Cask assembly temperature of $0^{\circ} \mathrm{C}$. Note that this corresponds to a $0^{\circ} \mathrm{C}$ internal gas temperature because a zero power MCO is conservative for calculation of the maximum backfill gas inventory. The minimum backfill gas inventory to be used for backfi1l gas loss calcuTations is developed in section 7.1.2.1.1.

The 65.5 gmol hydrogen inventory used for all hydrogen release and backfill gas loss calculations is based on a total gas inventory ( 95.8 gmo $)$ that corresponds to the $5.3 \mathrm{~atm}$ (absolute) maximum pressure reached in the plot on page K-17 of HNF-SD-TI-40. Rev. 3 (MCO Internal Gas Composition and Pressure During Interim Storage), given the 30.3 gmol backfil1 gas inventory upon which that plot is based. Note that this approach conservatively takes al1 other gases (oxygen. fission gas, or any other gas that may be included in the 95.8 gmol total) as hydrogen. 


\subsection{MCO BACKFILL TEMPERATURE AND MCO/CSB TUBE OPERATING TEMPERATURES}

The MCO gas temperature range $\left(0^{\circ} \mathrm{C}\right.$ minimum to $42^{\circ} \mathrm{C}$ maximum) used for calculation of backfill gas quantities is based on: 1) the minimum and maximum MCO Transport Cask temperatures $\left(0^{\circ} \mathrm{C}\right.$ minimum. $25^{\circ} \mathrm{C}$ maximum) allowed for performance of the final MCO back-fill operation at the CVDF - - see section 2.4.2.2 of the Spent Nuclear Fuel Project Product Specification (HNF-SD-OCD001. Rev. 1): 2) the $42^{\circ} \mathrm{C}$ average fuel temperature shown for a $25^{\circ} \mathrm{C}$ Transport Cask temperature on Figure B-810 of the Safety Analysis Report for Packaging (Onsite) Multi-Canister Overpack (HNF-SD-TP-017), and 3) the assumption that there will be no temperature differential between the MCO interior and the MCO Transport Cask for a zero power MCO (which is conservative for the maximum backfill inventory calculation).

The MCO gas temperature used for hydrogen release and backfill gas loss calculations is taken as the average fue t temperature $\left(64^{\circ} \mathrm{C}\right)$ that corresponds to the same point in time (40 years out) that the maximum pressure is reached in the plot on page K-17 of HNF-SD-TI-40. Rev. 3 (MCO Internal Gas Composition and Pressure During Interim Storage). The corresponding CSB storage tube gas temperature $\left(64^{\circ} \mathrm{C}\right)$ was conservatively assumed to be equal to the MCO gas temperature. That assumption is conservative because it results in a shorter time for the tube to reach 1 vol\% hydrogen than would be the case if the calculation were based on the actual storage tube gas temperature (something less than the MCO gas temperature).

The minimum MCO operating temperature used for the calculation to confirm that the MCO's internal pressure never goes negative was conservatively taken as the lowest ambient temperature on record $\left(-23^{\circ} \mathrm{F}, i . \mathrm{e} . .-31^{\circ} \mathrm{C}\right)$, per Table 3.9 of the Hanford Site C7imatological Data Summary 1996 With Historical Data (PNNL-11471).

\subsection{GAS PROPERTY DATA}

Gas property data were obtained from: ANSI N-14.5 Draft $1997 \mathrm{~J}$, Table B. I: from Fundamentals of Momentum. Heat and Mass Transfer. Appendix I (WeTty, et.al., 1969); from the CRC Handbook of Chemistry and Physics (49th Edition). and from page 208 of the Scott Specialty Gases catalog (Scott Environmenta? Technology Inc., 1985).

\subsection{BAROMETRIC DATA}

Local barometric effects (used for calculations in section 7.3.1) have most recent ly been documented in Barometric Pressure Variations (WHC-EP-0651). Table $\sigma$ of that report provides minimum. average, and maximum integrated short-term data for periods from one hour to one year. 


\subsection{CSB STORAGE TUBE VOID VOLUMES}

Section 13.2 of the Canister Storage Building Process Technical Manual (HNF-1719. Draft Rev D) provides storage tube void volume estimates for various payload configurations. Because that document does not actualiy address the worst case payload configuration used for the hydrogen concentration calculations in section 7.3 of this document (two mechanicaliy sealed MCOs within a single tube), the following individual volumes were obtained from the net volumes listed in Table 13-2 of the draft document:

Empty Storage Tube Void Volume (Less Plug) ............... $4460 \mathrm{~L}$

Lower Impact Absorber Displacement Volume -............ $280 \mathrm{~L}$

Intermediate Impact Absorber Displacement Volume ........ $90 \mathrm{~L}$

MCO Displacement volume Without Welded Cap ............ $1210 \mathrm{~L}$

MCO Displacement volume With Welded Cap -............. $1260 \mathrm{~L}$

Storage Tube Shield Plug Displacement Volume ... listed as "TBD" L

The draft technical manual lists the shield plug displacement volume as "TBD" because the shield plug design had not been finalized at that point in time. However, that design has now been finalized on H-2-120918, Rev 0 (Mechanical CSB Standard Tube Plug Assembly):

Length of In-Tube Portion ............... 41 inches, or $104 \mathrm{~cm}$ Diameter of In-Tube Portion ............. 26 inches, or $66 \mathrm{~cm}$

The approximate displacement volume of the shield plug is therefore:

$$
\pi(66 / 2 \mathrm{~cm})^{2} \times 97 \mathrm{~cm}=105.633 \mathrm{~cm}^{3}=356 \mathrm{~L}
$$

USE $360 \mathrm{~L}$

The worst case tube void volume for calculation of $\mathrm{H}_{2}$ concentrations within CSB tubes. which is based on a single tube containing two mechanically sealed MCOs and their associated impact limiters, is therefore:

$$
4460 \mathrm{~L}-360 \mathrm{~L}-280 \mathrm{~L}-1210 \mathrm{~L}-90 \mathrm{~L}-1210 \mathrm{~L}=1310 \mathrm{~L} \text { USE } 1300 \mathrm{~L}
$$

The following additional volume estimates apply for payload configurations evaluated by this document:

Two welded MCOs and their associated impact absorbers:

$4460 \mathrm{~L}-360 \mathrm{~L}-280 \mathrm{~L}-1260 \mathrm{~L}-90 \mathrm{~L}-1260 \mathrm{~L}=1210 \mathrm{~L}$ USE $1200 \mathrm{~L}$

One mechanical7y sealed MCO and both impact absorbers:

$4460 \mathrm{~L}-360 \mathrm{~L}-280 \mathrm{~L}-1210 \mathrm{~L}-90 \mathrm{~L}=2520 \mathrm{~L}$ USE 2500L

Finally, based on H-2-120918, Draft Rev 0, the hold-up volume for each of the shield plug's two identical vent ports can be estimated as:

Length - $30 \mathrm{~cm}\left(\sim 11^{\prime \prime}\right)+100 \%$ al lowance for nipple, etc. $=60 \mathrm{~cm}$ Diameter - $1.9 \mathrm{~cm}(0.75$ inch $)$

Volume $=\pi(1.9 / 2 \mathrm{~cm})^{2} \times 60 \mathrm{~cm}=170 \mathrm{~cm}^{3}$; For two ports USE $0.40 \mathrm{~L}$ 


\subsection{COMBUSTIBLE GAS MANAGEMENT FUNCTIONS AND REQUIREMENTS}

Significant quantities of hydrogen can be generated within MCOs during the first few years of storage as a result of chemical reactions between exposed uranium metal and any moisture that is retained by fuel particulate. Depending on the amount of sludge and retained moisture within a given MCO (and a number of other factors) both hydrogen and oxygen may cont inue to be generated by radiolysis within MCOS throughout the 40 year CSB operating 1 ife.

The SNF Project addresses the potential for combustion of the hydrogen with an overal1 strategy that, depending on the process step, employs one of two general approaches recommended by NFPA 69 to avoid accumulation of a combustible gas mixture. The functions and requirements that implement the project's overall combustible gas management strategy are listed below.

\subsection{FUNCTION: PRECLUDE COMBUSTIBLE MIXTURES INSIDE MCOS}

Because significant quantities of hydrogen are anticipated within MCOs, it will be necessary to provide this function by limiting the concentration of oxygen within MCOS. Reduction of oxygen concentrations within MCOs has been addressed by a number of different, but related, studies, analyses, and reports as the process design has evolved. culminating in Revision 3 of HNF-SD-SNF-TI-040 (MCO Interna7 Gas Composition and Pressure During Interim Storage). Revision 0 of that document initially evaluated the ability of exposed uranium metal surfaces within the MCO to remove any oxygen that is generated by radiolysis of water and established 4 vol\% as the Limiting oxidant Concentration (LOC) for the worst case gas mixture within an MCO and then used that value ( 4 vol\%) as the maximum allowable oxygen concentration. This allowable is $20 \%$ lower (4\% versus $5 \%$ ) than that permitted by the applicable NRC regulatory guide (Control of Combustible Gas Concentrations in Containment Following a Loss-of-Coolant Accident, NRC Regulatory Guide 1.7) because the LOC itself is lower for the MCO's worst case conditions. Consequent7y. Table 4-1 of the Spent Nuclear Fue7 Project Product Specification (HNF-SD-SNF-OCD-001) specifies a 4 vol\% maximum oxygen concentration instead of the 5 vol\% NRC limit.

\subsubsection{Functional Requirement: Preclude Air Ingress to MCOs}

Although, the analyses in HNF-SD-SNF-TI-040 do not specifically address accumulation of oxygen within MCOs due to air ingress, the results indicate that there is little or no excess gettering capacity to accommodate ingress of oxygen into the MCO. Consequently, one functional requirement of the MCO handling and storage system (including, but not limited to the MCO vessel and its seals) is to essentially preclude (as opposed to limit) air ingress to an MCO (unless MCOs are periodically purged and backfilled).

5.1.1.1 Implementation Criteria. If air ingress to MCOs is to essentially be precluded it will either be necessary to maintain an air free (i.e., oxygen free) atmosphere around MCOs at a11 times (which wi11 not be practical, or even possible) or to maintain MCOs at positive gage pressures at all times.

While it is possible to design and fabricate seals that are capable of 
precluding any measurable air ingress, this requirement can be more easily satisfied by simply maintaining the MCO at a positive gage pressure. This approach has the added advantage that it will automatical1y gain additional time for a leaking seal because the positive gage pressure must first be lost before any significant amount of air can even begin to enter the vessel.

The following criteria must be satisfied in order to maintain the MCO at a positive gage pressure, and thereby preclude air ingress, under all operating conditions.

5.1.1.1.1 Minimum Time To Maintain Positive Pressure. There are two cases that must be considered in order to establish the minimum time during which MCO seals must retain sufficient backfill gas to maintain positive gage pressure under all operating temperature conditions.

Case 1 -- Transport to the CSB and Initial Staging

- Minimum Requirement - 2 years

The MCOs wi1l employ mechanical seals during transport to the CSB. While most of the MCOS wi 11 be provided with welded end closures a short time after they are received at the CSB, a limited number of MCOS will undergo periodic inspection and gas sampling prior to installation of their welded caps. While it may prove necessary to maintain these mechanically sealed MCOs within the CSB for several years, it should not be difficult to ensure that each of them is serviced on an annual basis, given their small numbers.

In addition to the mechanically sealed MCOs discussed above, it may be necessary to provide a weld station queue area ( $i$.e.. designated storage tubes) capable of staging mechanically sealed Mcos while they await installation of their welded closures. Because the turnaround time in an active process queue should be on the order of days or weeks, and because the MCOs within the queue should be easy to keep track of during process delays (the queue's tubes could be provided with an inert purge during extended plant shutdowns), a one year minimum backfill retention time should be adequate for these in-process MCOs.

Based on the above considerations, and allowing for a $100 \%$ contingency, the minimum time for a mechanically sealed MCO to maintain positive backfill pressure is 2 years. While, two years is the minimum retention period. CSB operations would be simplified if there were no limit (beyond the CSB's current 40 year design 7 ife) to the time that mechanically sealed MCOs can retain positive backfill pressure. Consequently, it is a highly desirable (a)though not absolutely necessary) goal to confirm that a mechanically sealed MCO wi l1 maintain a positive backfill pressure for at least 40 years.

Note that MCO temperatures will vary as a result of decay heat variations among the MCOS, and as a result of seasonal variations in the CSB's cooling air inlet temperature. While the minimum molar quantity of backfill gas must be calculated at the minimum anticipated MCO gas temperature. the backfill gas leakage rate must be calculated at the gas temperature that corresponds to the maximum anticipated gas pressure). Also note that, even though the backfi11 gas leakage calculation must include the maximum possible generated gas inventory, no allowance can be included for any of the generated gas when 
establishing the minimum end-point pressure because al1, or most, of it could be gettered by uranium at any time during the project life.

Case 2 -- Long Term ("Interim") Storage

- Minimum Requirement - 40 years

For the purposes of this document, long term storage (i.e.. "Interim Storage") will not begin for any given MCO until its weld closure has been installed. Following weld closure installation. MCOs must retain an adequate quantity of backfill gas to maintain a positive gage pressure for 40 years.

Design Goal for Retention of Additional Backfill Gas

Considerable time and expense that would otherwise be required to perform additional computer analyses will be avoided if it can also be demonstrated that the minimum backfi11 pressure is sufficient to ensure retention of a 30.3 gmol minimum inventory after 40 years (as opposed to only that required to maintain a positive gage pressure). Therefore, an additional 40 year goal is to ensure that no MCO will ever contain less than 30.3 gmol of He, which is the minimum inventory used for the current design basis evaluation of oxygen concentrations within MCOS (see HNF-SD-SNF-TI-040, Rev 3).

5.1.1.1.2 Type of Backfill Gas. The backfill gas must be inert. Gasses that might be consumed by reacting or otherwise interacting with uranium metal (e.g., hydrogen or nitrogen) are unacceptable because there is no way to be certain that they wi11 be replaced by generation of additional hydrogen. or that any additional hydrogen that is generated wi 11 not be gettered by the uranium. At this point in the project. helium has been selected as the backfill gas. Consequently, the leakage calculations that support this document are based on a helium backfill. In the event some other inert gas were to be selected, the helium based calculations would be conservative in view of the fact that helium has the highest leakage rate of any inert gas.

5.1.1.1.3 Maximum Backfill Pressure. The maximum MCO backfill pressure and the minimum MCO gas temperature during the backfill operation have been established as $12.5 \mathrm{psig}\left(27.2 \mathrm{psia}-1.85 \mathrm{~atm}\right.$ ) and $0^{\circ} \mathrm{C}$, respective $7 \mathrm{y}$ (see sections 4.3 and 4.4). The maximum MCO backfil1 pressure and minimum MCO gas temperature are based on limiting the inert gas allocation to a maximum value of 41.3 gmol for an MCO with a $500 \mathrm{~L}$ minimum internal void volume. While the actual backfi11 quantity wi11 vary upwards from the 41.3 gmol value for MCOs with free volumes greater than the $500 \mathrm{~L}$ minimum. the larger backfill quantity will not result in over pressurization because the backfill gas quantity represents less than half of the worst case gas allocation used to calculate the maximum pressure. In other words, for a given backfill pressure and temperature, larger MCo volumes will result in lower worst case pressures (note that backfill pressure and temperature were specified instead of gmol in order to take advantage of this automatic compensation effect).

5.1.1.1.4 Minimum Backfill Pressure. The minimum backfill pressure must be high enough to ensure that the resulting molar quantity of backfi11 gas will be sufficient to allow for seal leakage and still maintain a positive pressure within MCOs that are at temperatures as low as $-31^{\circ} \mathrm{C}$ (see section 4.4 ). Based on the 12.5 psig maximum backfill pressure, and based on the following logic. it will be necessary to demonstrate that a 9.5 psig (24.2 psia - 1.65 atm) 
minimum backfill pressure is sufficient to meet the above requirement.

The nominal fill pressure must be low enough to provide a reasonable margin between the nominal value and the specified maximum value (12.5 psig). An allowance of 1.5 psi is considered necessary in order to accommodate instrument error and stil1 provide a contingency allowance between the actual maximum condition and the specified maximum fil pressure. Consequently, an 11 psig (25.7 psia - - $1.75 \mathrm{~atm}$ ) nominal fill pressure was assumed for the purpose of establishing the minimum fill pressure and confirming that it is sufficient to meet the requirements listed in the preceding. Based on a similar safety margin (i.e.. 1.5 psi) between the nominal value and the minimum required fill pressure, a minimum initial backfill pressure of 9.5 psig (24.2 psia - - $1.65 \mathrm{~atm}$ ) was selected for evaluation. Evaluation of the seal's ability to retain helium over time must. therefore, be based on an iritial molar quantity of helium that corresponds to an initial fill pressure of $1.65 \mathrm{~atm}$ absolute at some maximum allowable MCO fil1 temperature. The maximum allowable MCO Transport Cask temperature has been specified as $25^{\circ} \mathrm{C}$. which corresponds to a $42^{\circ} \mathrm{C}$ maximum MCO gas temperature (see section 4.4). This works out to 31.9 gmol of helium for the $500 \mathrm{~L}$ minimum MCO void volume (see section 6.1.2.1). For those MCOs (i.e., most of them) that exceed the minimum void volume, the actual backfill gas quantity will increase proportionally with the increase in void volume. which means that an initial backfill pressure that is adequate for a minimum void volume MCO will also be adequate for a maximum volume MCO.

As noted in section 5.1.1.1.1, an additional design goal is to ensure that the MCO will never contain less than 30.3 gmol of $\mathrm{He}$. which is the helium inventory used in the current design basis evaluation of oxygen concentrations within MCOS (see HNF-SD-SNF-TI-040. Rev. 3). Therefore, the 1.65 atm minimum backfill pressure will be evaluated against that goal as well.

\subsubsection{NFPA 69 Paragraph 2-7.2 Compliance Status}

Chapter 2 of NFPA 69 covers application of that standard's oxidant reduction technique. Paragraph 2-7.2 provides the operating limits and instrumentation requirements for systems that will be operated below the LOC. Paragraph 2-7.2.2 requires that the LOC for a given system be based on the worst credible case gas mixture yielding the smallest LOC. Paragraph 2-7.2.3 requires that a safety margin be maintained between the LOC and normal working concentration in the system. See Appendix B of this document for an overal1 summary description of NFPA 69.

5.1.2.1 Non-Compliance with Specific Requirements. Paragraph 2-7.2.5 of NFPA 69 states: "Where the oxidant concentration is continualy monitored, a safety margin of at least 2 volume percent below the measured worst credible case LOC shall be maintained unless the LOC is less than 5 percent, in which case the equipment shall be operated at no more than 60 percent of the LOC." Paragraph 2-7.2.5 can not be applied to an MCO after it leaves the CVDF because it will have no provision for continuous monitoring.

Paragraph 2-7.2.6 states, in part: "Where the oxygen concentration is not continuously monitored. the oxygen concentration sha11 be designed to operate at no more than 60 percent of the $\angle O C$, or 40 percent of the $L O C$ if the $L O C$ is below 5 percent." 
- Based on the 4 vol\% LOC discussed in section 2.1 above, compliance with the letter of the above statement would require that the overal1 SNF Project fuel removal and storage process (e.g., the fuel cleaning process, maximum MCO fuel and/or scrap inventory, fuel drying process. Mco backfill gas type and/or quantity, etc.) be designed to ensure that the oxygen concentration within Mcos wi11 not exceed 1.6 vol\% at any time during their service life.

In view of the fact that the current oxygen gettering goal is to maintain the oxygen concentration within all MCOs at or below the LOC (as opposed to $40 \%$ of the LOC), the SNF Project does not appear to comply with the above NFPA 69 requirement.

- With respect to the above, apparent, non-compliance, it is important to recognize that NRC Regulatory Guide 1.7 is also apparently out of compliance.

Even given a 5 vol\% LOC, the NRC guide's maximum allowable oxygen concentration would have to be specified as $60 \%$ of the 5 vol\% LOC, or 3 vol\% oxygen, as opposed to 5 vol\%.

Paragraph 2-7.2.6 further states: "If the oxygen concentration is not continuously monitored, the oxygen concentration sha 17 be checked on a regularly scheduled basis."

- The SNF Project will be unable to comply with this requirement once a given MCO's weld closure has been installed.

5.1.2.2 NFPA 69 Paragraph 2-7.2 Equivalency. Although it is impossible to claim strict compliance with NFPA 69 Paragraph 2-7.2 in light of the situation described in section 5.1.2.1 above, it is possible to demonstrate that both the SNF Project and the NRC Regulatory Guide 1.7 do provide an equivalent level of protection. Paragraph 1-1.3 of NFPA 69 provides for demonstration of equivalency (see Appendix $B$ of this document).

In order to demonstrate equivalency to the oxygen concentration limits and monitoring requirements invoked by Paragraph 2-7.2. despite the project's inability to strictly comply with those limits and requirements, it is necessary to compare the operational bases that drove the NFPA 69 requirements to those that drove the MCO's 4 vol\% oxygen limit and the similar 5 vol\% 7 imit established by the NRC Regulatory Guide.

In the instance of the 5 vol\% oxygen 7 imit invoked by NRC Regulatory Guide 1.7 (Control of Combustible Gas Concentrations in Containment Following a LOSS-of-Coolant Accident). the difference is apparent from the phrase "loss of coolant accident" in the guide's title. Whereas the concentration limits and monitoring requirements of NFPA 69 are based on norma 1 operation at concentration levels that approach the specified maximum ( 3 vol\% oxygen for the NRC's 5 vol\% oxygen LOC), the NRC's 5 vol\% limit has nothing to do with normal operation but is, instead, directed toward a design basis accident.

The MCO's situation is similar, but not identical, to that addressed by the NRC. There is no basis for a "normal operating limit" for oxygen within a reactor containment because there is normally no hydrogen to react with that oxygen, which is why the scope of NRC Regulatory Guide 1.7 is 1imited to 1oss 
of coolant accident. While it may be necessary to inert the containment building during normal operation in order to ensure that oxygen levels can not exceed 5 vol\% during or after a postulated accident, the inerting requirement is directed purely at the accident condition, as opposed to normal operation.

The MCO, on the other hand, must be assumed to contain significant quantities of hydrogen during normal operation, therefore any limitation on the oxygen concentration must, by definition, be directed at normal operation. Whereas the difference between the NRC basis and the NFPA 69 basis is that of an accident condition versus a normal operating condition, the difference between the MCO's basis and NFPA $69^{\circ} \mathrm{s}$ basis concerns the methodology that is used to preclude combustion.

For most applications governed by NFPA 69 , it is simply a matter of maintaining a purge gas blanket and/or flow that normally wi 11 not exceed the particular limit imposed. The logic is that, in the event that something goes wrong with the purge gas system (e.g., a leaking flange on the intake side of an "inert gas" compressor's first stage, etc.), the additional margin afforded by NFPA 69's requirements wil1 generally be sufficient to prevent the LOC from being greatly exceeded for any significant period of time. No one has to demonstrate by a rigorous analytical model that it will not be reached.

In view of the above, it may be possible to provide documentation that satisfies NFPA 69, Paragraph 1-1.3. which addresses situations where it is either impossible or inappropriate to meet any or all of the detailed requirements that it invokes. That paragraph states: "Nothing in this standard shall be intended to prevent the use of systems, methods, or devices of equivalent or superior quality, strength, fire resistance, effectiveness, durability, and safety over those prescribed by this standard, provided technical documentation is made available to the authority having jurisdiction to demonstrate equivalency and the system, method, or device is approved for the intended purpose."

\subsection{Strategy To Achieve NFPA 69 Paragraph 2-7.2 Equivalency. Forma 1} recommendation of the SNF Project strategy to document and obtain official recognition of NFPA 69 Paragraph 2-7.2 equivalency is beyond the scope of this document. Depending on the findings of ongoing analyses, it may, or may not, be possible to document equivalency by demonstrating that the vast majority of MCOS wi 11 not contain oxygen at concentrations above 1.6 vol\%, and that the 4 vol\% LOC would only be approached (or possibly reached) by a bounding case MCO. Failing that, it may be possible to demonstrate that an MCO can safely contain a deflagration (as opposed to a detonation) for a worst case set of conditions in accordance with Chapter 5 of NFPA 69 . Because, Paragraph 1-1.2 of NFPA 69 excludes detonations from its scope, evaluation of the corresponding detonation would then be performed to DOE and NRC requirements.

\subsection{FUNCTION: PRECLUDE COMBUSTIBLE MIXTURES OUTSIDE MCOS}

In order to permit MCOs to be handled and stored within air filled shipping casks and storage tubes. it wi 11 be necessary to provide this function by 7 imiting the concentration of hydrogen within the casks and tubes. 


\subsubsection{Functional Requirement: Limit $\mathrm{H}_{2}$ Release From MCOS}

In order to limit the concentration of hydrogen within the air filled casks and tubes that handle and store MCOs, it wi 11 either be necessary to continuously or periodically exchange the cask or tube air, or it will be necessary to limit the release of hydrogen from MCOs. Because it would be very difficult to ensure absolutely reliable air exchange, the project wi 11 provide that function by limiting the release of hydrogen from MCOs.

\subsubsection{Implementation Criteria.}

\subsection{Acceptable $\mathrm{H}_{2}$ Concentration. $\leq 1.0$ vol\% $\mathrm{H}_{2}$}

\subsection{Minimum Time To Maintain Acceptable $\mathrm{H}_{2}$ Concentration.}

CASE 1 -- Mechanically Sealed MCOs (Singly Occupied CSB Tube): 1 year

This would require that a given tube containing a mechanically sealed MCO be sampled and ventilated every 8 months or so. Note that. while one year is the minimum criterion for a singly occupied tube containing a mechanically sealed MCO, it is recognized that maximum operating flexibility and minimum cost would be realized if the mechanical seals (in conjunction with dilution via the storage tube vent ports) can be shown to limit steady state hydrogen concentrations to 1 vol\% or less within un-sealed tubes containing two mechanically sealed Mcos.

CASE 2 -. Welded MCOS (DoubTy Occupied CSB Tube): 40 years

\subsubsection{NFPA 69 Paragraph 3-3 Comp1iance Status}

Chapter 3 of NFPA 69 covers application of the combustible reduction technique. Paragraph 3-3 provides design and operating requirements for systems that wi11 be operated below the Lower Flammable Limit (LFL). See Appendix B of this document for an overall summary description of NFPA 69.

Paragraph 3-3.1 of NFPA 69 requires that the combustible concentration be maintained at or below 25\% of the LFL ( 1 .e. . 25\% of 4 vol\% for hydrogen in air works out to 1 vol\%). An exception is provided to allow combustible concentrations up to $60 \%$ of the LFL for systems that have the capability to automatically shut off the source of combustible material or otherwise prevent a combustion event (automatic activation of quenching systems, etc.) by means of instrumentation with safety interlocks.

In view of the current hydrogen management goal to maintain the hydrogen concentration within any CSB storage tube (including those that contain safety basis pressure MCOS) at or below 25\% of the LFL (i.e., at or below 1 vol\% hydrogen), and in view of the results in this document, which confirm the ability of the MCO seals to meet the 1 vol\% maximum concentration goal, it should be easy to demonstrate that the SNF Project is in compliance with the above NFPA 69 requirement, provided that a 11 the necessary documents are in place (e.g., gas inventory calculations, hydrogen leak rate and build-in calculations [provided by this document], leak test reports, etc.). 


\subsection{PREDICTION OF OPERATIONAL LEAKAGE FROM LEAK TEST RESULTS}

The current Performance Specification for the Spent Nuclear Fuel MultiCanister Overpack (HNF-S-0426) specifies the following leak test acceptance criteria for the $M C O$ :

- $1 \times 10^{-5} \mathrm{scc} / \mathrm{sec}$ maximum integrated leak rate prior to installation of final closure weld.

- $\quad 1 \times 10^{-7} \mathrm{scc} / \mathrm{sec}$ maximum integrated leak rate following installation of final closure weld.

In order to either confirm that the above leak test acceptance criteria are adequate or establish revised criteria, the calculations must: 1) assume that some of the MCOS will include leak paths that would produce testing results corresponding to those criteria (i.e., that some MCOs almost fail the leak test - considered unlikely); 2) predict leakage rates that would result from those leak paths under the actual operating conditions (e.g.. gas composition, pressure, temperature, etc.): and 3) evaluate the predicted leakage rates against the MCO's gas management functions and requirements.

\subsection{LEAKAGE CORRELATION DEFINITIONS AND METHODOLOGY}

Section 3 (Definitions) of the American National Standard For Radioactive Materials - - leakage tests on packages for shipment (ANSI N14.5-1987) defines

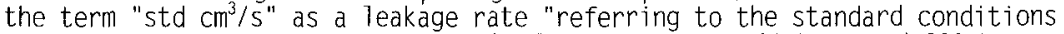
for dry air at 1 atmosphere (atm) absolute pressure (101 kPa) and $298 \mathrm{~K}$ $\left(25^{\circ} \mathrm{C}\right)$." That section also defines "leaktight" as "a leakage rate less than or equal to $1 \times 10^{-7} \mathrm{std} \mathrm{cm}^{3} / \mathrm{s}$. at an upstream pressure of $1 \mathrm{~atm}$ abs and a downstream pressure of $0.01 \mathrm{~atm}$ abs or less, irrespective of the radioactive contents."

Section 4.13 of the current MCO performance specification (HNF-S-0426) requires all MCO seals to be "... leakage rate testable in accordance with ANSI N14.5". Therefore it follows from the above definitions that the MCO's specified $1 \times 10^{-5} \mathrm{scc} / \mathrm{sec}$ and $1 \times 10^{-7} \mathrm{scc} / \mathrm{sec}$ leakage acceptance criteria refer to the volume of dry air (as opposed to helium or hydrogen). corrected to an absolute pressure of one atmosphere and $25^{\circ} \mathrm{C}$, that wi $71 \mathrm{flow}$ through a leak path from an upstream cavity with an absolute pressure of one atmosphere into a downstream cavity that has been evacuated to $0.01 \mathrm{~atm}$ abs, or less.

While the ANSI standard provides a wide range of options with respect to basic testing methods (pressure decay, gas detection, etc.), physical testing arrangements (inward flow. outward flow. etc.), and test conditions (test medium. temperature, pressure, etc.), the test results are always reported as an air leakage rate that would have occurred at the exact combination of upstream pressure, downstream pressure, and temperature that is spelled out in the above paragraph. 
HNF-2155 Rev 1

\subsubsection{Shortcomings of The ANSI N14.5-1987 Approach}

All of the calculations in this document that predict operational leakage (i.e.. leakage "at pressure") from standard leak test acceptance criteria are based on the flow correlation equations that are provided by Appendix $B$ of ANSI N14.5-1997. Draft J, as opposed to the equations and guidance provided by the released version (ANSI N14.5-1987). Justification for using the current draft version instead of the released version is provided below.

ANSI N14,5 provides guidance for correlation of leakage under test conditions to leakage under actual operating conditions. To accomplish this. it provides a set of equations to establish the diameter of a fictitious single "hole" that would result in the observed test flow rate. The fictitious hole is assigned an arbitrary length, typically $1 \mathrm{~cm}$ (preliminary calculations for this document used values from $1 \mathrm{~cm}$ down to $0.025 \mathrm{~cm}$ ). The standard then predicts the flow rate at the operating conditions by applying the calculated hole diameter and assumed length to the same equations (or others. depending on the flow regime) after adjusting various parameters (temperature, pressure, gas composition; etc.) to represent the actual operating conditions.

Specifically. Appendix B of the 1987 release provides Eq B2, total flow: $E q B 3$. continuum $f 70$, and $E q B 4$, molecular flow. all of which are 7 imited to calculation of unchoked flow. It provides $E q B 7$ for choked flow. Finally, it provides $E q B 5$ to determine whether or not choked flow is possible, based on the ratio of continuum flow to molecular flow (the critical pressure ratio must also be satisfied). Because most leak testing is performed under conditions that favor molecular flow. the apparent hole diameter is typically calculated via EqS B2 through B3. The 1987 version of the standard then uses an orifice type equation ( $E q B 7)$ to predict the $f 7$ ow rate under high pressure plant conditions at which the flow is mostly continuum and therefore choked (per Eq B5 -- the critical pressure ratio is satisfied in both cases).

The shortcomings of the above approach are inherent (although they were not immediately apparent) in Table B2 (Air Leakage for Various Hole Diameters) of the 1987 release. which provides calculated flow rates based on the equations and guidelines provided by the standard. The calculated values in the first column of the table indicate a discontinuity in the flow region between $10^{-3}$ std $\mathrm{cc} / \mathrm{sec}$ and $10^{-8}$ std $\mathrm{cc} / \mathrm{sec}$. This would imply a "transitiona $7 "$ flow regime spanning many decades. That table has been completely revised in the 1997 draft of the standard.

Problems were first encountered during the initial attempt to determine whether the standard leak conditions would result in choked flow or unchoked flow at the mechanical seal's [then] specified $1 \times 10^{-4} \mathrm{scc} / \mathrm{s}$ leak rate. When the equations for unchoked flow were used. Eq B5 determined that the flow was choked, whereas that same equation determined the flow to be unchoked when applied to results from the choked flow equation. This condition is typically referred to as "transitional flow, "although in many cases it is really an artifact of the predictive methodology and has nothing to do with actual flow.

While the above "transitional flow" problems were not encountered with initial calculations for the $1 \times 10^{-7} \mathrm{std} \mathrm{cc} / \mathrm{sec}$ leak test acceptance criterion. the underlying problems in the overall approach eventually became apparent. The flow regime was plainly unchoked at the test conditions and 
plainly choked at the operating conditions. which was encouraging. However, the subsequent calculation predicted that a pipe weld would exhibit gross leakage at the operating conditions, despite the fact that the weld had satisfied a $1 \times 10^{-7} \mathrm{std} \mathrm{cc} / \mathrm{sec}$ leak test acceptance criterion. The reason for this situation is that the choked flow equation ( $E q B D$ ) does not consider the hole's length at a11. Whereas the hole's diameter was obtained using equations ( $E q B 2$, et. a1.) wherein the calculated flow rate for a given hole diameter is an inverse linear function of the hole's length.

\subsubsection{The Revised Approach In ANSI N14.5-1997 Draft J}

In order to eliminate the problems inherent in the 1987 release, Section B4 (Correlation Between Gas Leakage Rates at Different Conditions) of ANSI N14.5-1997 J eliminates all guidance for correlation of molecular flow conditions to choked flow conditions and eliminates the choked flow equation (Eq B7). Section B3 (Gas Leakage) provides a new flow equation $(B-5)$, however this equation is not a replacement for $E q B 7$ and has nothing to do with choked flow. nor with the original $E q B 5$ (see section 6.1 .1 above), which has also been eliminated. The new equation $B-5$ is just an extension of the original $E q B 2$. which (now labeled $B-2$ ) remains the basic flow equation. Equation B-5 was introduced in order to formalize the pressure basis relationships among the various volumetric flow rates that can be calculated for the same molar flow rate, depending on whether the flow rate is calculated at the upstream pressure, the downstream pressure, or the average pressure.

The net result of these changes is that the first column of the revised Table B2 (now labeled Table B.2) provides five different calculated leakage rates between $1.2 \times 10^{-3} \mathrm{scc} / \mathrm{sec}$ and $2 \times 10^{-8} \mathrm{scc} / \mathrm{sec}$ whereas the old (released) version provided none in that range. And. whereas the old version listed a calculated leakage rate of $1.4 \times 10^{-3} \mathrm{scc} / \mathrm{sec}$ for a $3 \times 10^{-4} \mathrm{~cm}$ hole diameter. the new version lists a calculated leakage rate below $10^{-6} \mathrm{scc} / \mathrm{sec}$ for the same hole (note that the hole's length is listed as $1 \mathrm{~cm}$ in both cases). Again. the reason for the gross discrepancy (over three orders of magnitude) between the released version of the table and the new draft version is that the released version calculated these leakage rates (i.e., those 1 isted in the first column) by using $E q B 2$ for some holes, and $E q B 7$ (which disregards the hole's length) for others. whereas the draft revision calculates all leakage rates using equation B-5 (equivalent to Eq B2). 


\subsection{CALCULATIONS}

\subsection{MCO OPERATING CONDITIONS}

\subsubsection{MCO Gas Temperatures}

The maximum and minimum operating MCO gas temperatures to be used for calculation of MCO gas pressures or gas leakage rates within the CSB have been established as $64^{\circ} \mathrm{C}$ and $-31^{\circ} \mathrm{C}$ respectively. See section 4.4 .

\subsubsection{MCO Gas Inventories}

See section 4.3 for references and additional discussions that justify use of the following gas inventories for MCO leakage calculations.

7.1.2.1 Worst Case Gas Inventory For Calculating Helium Loss. The following gas inventory assignments are appropriate for evaluation of the MCO's leak test acceptance criteria against its backfill gas (He) retention requirements (see section 7.1.2.1.1, below, for the calculation that develops the minimum initial helium backfill inventory).

- Hydrogen (maximum safety basis inventory) -...- $65.5 \mathrm{gmol}$

- Backfill gas (minimum fill quantity of He) -....-31.9 gmol

- Alpha decay helium (taken as hydrogen) ........... 0 gmol

- Noble gasses ( $k r$. Xe -- taken as hydrogen) -...... 0 gmol

- Oxygen (taken as hydrogen) ......................... gmol

- total 97.4 gmol

7.1.2.1.1 Minimum Initial Backfi11 Gas Quantity. The minimum initial backfill quantity is calculated below. This minimum quantity is based on a minimum backfill pressure at a maximum MCO Transport Cask temperature, where the cask temperature is used to determine the gas temperature within the MCO. Although the calculated minimum molar quantity [for a $500 \mathrm{~L}$ minimum void space $\mathrm{MCO}$ ] will not appear as an operations requirement, it will probably have the same administrative force because the minimum pressure and maximum cask temperature are expected to become operations requirements. See sections 4.4 and 5.1.1.1.4 for the maximum temperature and minimum pressure bases.

Maximum MCO gas temperature during backfi11 -- $T=315 \mathrm{~K}\left(42^{\circ} \mathrm{C}\right)$

Minimum MCO void volume - - V $=500 \mathrm{~L}$

Minimum backfi11 pressure -- $P=(24.2 \mathrm{psia}) /(14.7 \mathrm{psia} / \mathrm{atm})=1.65 \mathrm{~atm}$ $R=0.82 \mathrm{~L}$ atm/gmol $K$

$P V=n R T ; n_{\text {initial }}=P V / R T=$ minimum initial backfill gas inventory, gmol; $n_{\text {initial }}=(1.65 \mathrm{~atm})(500 \mathrm{~L}) /[(0.082 \mathrm{~L} \mathrm{~atm} / \mathrm{gmol} \mathrm{K})(315 \mathrm{~K})]=31.94 \mathrm{gmol}$ 
7.1.2.1.2 Minimum Required MCO Helium Inventory. Section 5.1.1.1 requires that the MCO be maintained at a positive gage pressure at a11 times, and section 5.1.1.1.2 stipulates that the positive gage pressure be based solely on an inert backfill gas because the hydrogen could be gettered by uranium metal. Therefore, the leak test acceptance criteria must be evaluated to ensure that the minimum backfill case MCO (31.9 gmol of He) will still retain a sufficient amount of helium to maintain a positive gage pressure at the worst case minimum operating temperature after the specified storage time(s) at the highest anticipated pressure(s). The minimum required inventory can be calculated directly from the worst case minimum MCO operating temperature and the MCO's minimum void volume. Note that the minimum void volume can be used here (despite the fact that the maximum void volume would normally control) because the minimum initial backfill quantity $(31.9 \mathrm{gmol})$ is itself based on a minimum fill pressure within a minimum void volume MCO. Where the actual void volume exceeds the $500 \mathrm{~L}$ minimum void volume (which will almost always be the case), the initial backfill quantity will also exceed the minimum initial backfill quantity by a proportional amount. Of course, the minimum required helium inventory wi11 also be higher for that MCO, but so wi11 the amount of expendable helium. The minimum required helium inventory is based on the following (See section 4.0 for bases):

$$
\begin{aligned}
& \text { Minimum MCO temperature during CSB storage -- } \mathrm{T}=242 \mathrm{~K}\left(-31^{\circ} \mathrm{C}\right) \\
& \text { MCO void volume (see above discussion) -- } V=500 \mathrm{~L} \\
& \text { Minimum Acceptable Helium Pressure -- } \mathrm{P}=1.0 \mathrm{~atm} \\
& \mathrm{R}=0.82 \mathrm{~L} \mathrm{~atm} / \mathrm{gmol} \mathrm{K} \\
& P V=n R T ; n_{\text {final }}=P V / R T=\text { minimum required backfill gas inventory, gmol: } \\
& n_{\text {final }}=(1.0 \mathrm{~atm})(500 \mathrm{~L}) /[(0.082 \mathrm{~L} \text { atm } / \text { gmol } \mathrm{K})(242 \mathrm{~K})]=25.2 \mathrm{gmo} 1 .
\end{aligned}
$$


7.1.2.1.3 Maximum Acceptable Helium Loss. Given an MCO with a $500 \mathrm{~L}$ minimum void volume (see section 4.3), and given the minimum initial helium backfil1 inventory and minimum required helium inventory developed in sections 7.1.2.1.1 and 7.1.2.1.2. the maximum acceptable helium loss is:

$$
\begin{aligned}
n_{\text {loss }}= & n_{\text {initial }}-n_{\text {final }}=31.9 \text { gmol }-25.2 \text { gmol }=6.7 \text { gmol. where: } \\
& n_{\text {loss }}=\text { maximum acceptable total helium leakage over time; } \\
& n_{\text {initial }}=\text { minimum initial backfi } 11 \text { quantity (per sec 7.1.2.1.1); and } \\
& n_{\text {final }}=\text { minimum required helium inventory (per } \sec 7.1 .2 .1 .2 \text { ). }
\end{aligned}
$$

7.1.2.1.4 Design Goal for Maximum Helium Loss. MCO seals will also be evaluated against the 30.3 gmol helium retention design goal discussed in the last paragraph of section 5.1.1.1.1. Per the logic presented in section 7.1.2.1.3, above, the maximum desirable helium loss is:

$$
\begin{aligned}
n_{\text {loss }}= & n_{\text {initial }}-n_{\text {final }}=31.9 \mathrm{gmol}-30.3 \mathrm{gmol}=1.6 \mathrm{gmol} \text {, where: } \\
& n_{\text {loss }}=\text { design goal for maximum total helium leakage over time; } \\
& n_{\text {initial }}=\text { minimum initial backfill quantity (per sec 7.1.2.1.1); and } \\
& n_{\text {final }}=\text { minimum helium inventory goal }(30.3 \text { gmol). }
\end{aligned}
$$

Uniess the welding procedure includes an operation to "top-off" the MCO's helium backfill prior to welding (which it will not for most MCOS), the helium loss criteria must assume an appropriate combination of staging time (prior to installing the weld cap) and storage time (following weld cap installation). The following combination of times is considered conservative for calculating the worst-case amount of helium that could be lost from any MCO with acceptable leak test results. Allocation of the allowable loss is based on initial leakage calculations, which indicate that essentially no helium will be lost from a welded MCO during forty years of storage.

- $\quad$ Staging Time Requirement (i.e.. prior to welding) -- 4 years

- Portion of 1.6 gmol maximum loss allocated to Staging -- 1.3 gmol

- Interim Storage Time (after welding) - 40 years

- Loss allocation available for Interim Storage - 0.3 gmol 
7.1.2.2 Worst Case Gas Inventory For Calculating Hydrogen Release. The following gas inventory assignments represent a worst case condition for evaluation of the MCO's leak test acceptance criteria against the project's functional requirements to 1 imit the hydrogen concentration to 1 vol\% within the space that surrounds a bounding pressure case MCO. Application of this inventory to mechanically sealed MCOs during the first two or three years of their operation is very conservative because the inventory represents all of the hydrogen that could possibly be generated within the MCO during 40 years. whereas only about one tenth of that inventory is expected to be generated during the first several years of service.

- Hydrogen -- 65.5 gmor

- Backfill gas (maximum fill quantity of He) -..--- 41.3 gmol

- Alpha decay helium -. (taken as hydrogen) -........- 0 gmol

- Noble gasses $(\mathrm{Kr}, \mathrm{Xe}$ ) -. (taken as hydrogen)........ 0 gmol

- Oxygen .. (taken as hydrogen) .................. 0 gmol

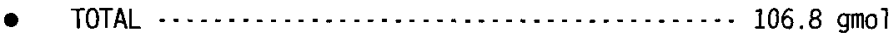

\subsubsection{MCO Operating Pressures}

7.1.3.1 Maximum Pressure For Helium Loss Calculations. Based on a 97.4 gmol total gas inventory (see section 7.1.2.1), on a $64^{\circ} \mathrm{C}$ (337 $\mathrm{K}$ ) operating temperature (see section 4.4), and on a $500 \mathrm{~L}$ internal void volume (see section 4.3$)$, the maximum operating pressure $\left(P_{\text {upstrean }}\right)$ required for helium loss calculations is:

$$
P_{\text {upstream }}=n R T / V=(97.4 \mathrm{gmol})(0.082 \mathrm{~L} \mathrm{~atm} / \mathrm{gmol} . \mathrm{K})(337 \mathrm{~K}) / 500 \mathrm{~L}=5.38 \mathrm{~atm}
$$

7.1.3.2 Maximum Pressure For Hydrogen Release Calculations. Based on a 106.8 gmol total gas inventory (see section 7.1.2.2), on a $64^{\circ} \mathrm{C}(337 \mathrm{~K}$ ) maximum MCO temperature, and on a $500 \mathrm{~L}$ minimum $\mathrm{MCO}$ void volume, the worst case operating pressure $\left(P_{\text {upstream }}\right)$ required for hydrogen release calculations is: $P_{\text {upstream }}=n R T / N=(106.8 \mathrm{gmol})(0.082 \mathrm{~L} \mathrm{~atm} / \mathrm{gmol} \mathrm{K})(337 \mathrm{~K}) / 500 \mathrm{~L}=5.90 \mathrm{~atm}$

\subsection{DOCUMENTATION AND VALIDATION OF FLOW CORRELATION CALCULATIONS}

Appendix A provides spread sheet listings of the calculations that were performed to predict actual in-service leak rates from leak rate acceptance criteria. The symbol definitions, equations, and hand calculations provided in the following sections demonstrate, document, and validate the equations that were input to the Excel $]^{\circ}$ program to produce the spread sheet listings.

\subsubsection{ANSI N-14.5 Oraft $1997 \mathrm{~J}$ Equations and Guidelines}

The equations recommended by Appendix B of ANSI N-14.5 Draft $1997 \mathrm{~J}$ are listed below, along with definitions for their parameters and references to the particular sections of Appendix B that govern their application. 
7.2.1.1 Definition of Symbols. The following symbols and their definitions are taken from section B2 of ANSI N-14.5 Draft $1997 \mathrm{~J}$ :

$\mathrm{a}=$ leakage hole Tength, $\mathrm{cm}$

$D=$ leakage hole diameter, $\mathrm{cm}$

$F_{c}=$ coefficient of continuum flow conductance per unit pressure, $\mathrm{cm}^{3} / \mathrm{atm} . \mathrm{s}$

$F_{m}=$ coefficient of free molecular flow conductance per unit pressure. $\mathrm{cm}^{3} / \mathrm{atm} .5$

$k=$ ratio of specific heat at constant pressure to specific heat at constant volume

$L=$ volumetric leakage rate, $\mathrm{cm}^{3} / \mathrm{s}$

$L_{d}=$ downstream volumetric leakage rate, $\mathrm{cm}^{3} / \mathrm{s}$

$L_{m}=$ measured leakage rate. $\mathrm{cm}^{3} / \mathrm{s}$

$L_{R}=$ reference air. leakage rate at standard conditions of $25^{\circ} \mathrm{C}$ and $1 \mathrm{~atm}$ abs. std $\mathrm{cm}^{3} / \mathrm{s}$

$L_{u}=$ upstream volumetric leakage rate, $\mathrm{cm}^{3} / \mathrm{s}$

$M=$ molecular weight, $\mathrm{g} / \mathrm{gmol}$

$P=$ fluid pressure, atm abs

$P_{\mathrm{a}}=$ average stream pressure $=1 / 2\left(P_{\mathrm{u}}+P_{d}\right)$, atm abs

$P_{d}=$ fluid downstream pressure, atm abs

$\mathrm{P}_{\mathrm{i}}=$ partial pressure of one component of a gas mixture, atm abs

$P_{m}=$ total pressure of a gas mixture, atm abs

$P_{\mathrm{u}}=$ fluid upstream pressure, atm abs

$Q=$ mass - like leakage rate, $\operatorname{atm} . \mathrm{cm}^{3} / \mathrm{sec}$

$R_{0}=$ universal gas constant, $8.31 \times 10^{7} \mathrm{erg} / \mathrm{gmol} . \mathrm{K}$

$R_{L . a t r n}=$ universal gas constant, $0.082 \mathrm{~L} . \mathrm{atm} / \mathrm{gmol} . \mathrm{K}$

$T=$ fluid absolute temperature, $K$

$T_{\mathrm{s}}=$ standard temperature, $298 \mathrm{~K}$

$\mu=$ fluid viscosity, $C P$ (centipoise)

$r_{f}=$ ratio of $F_{c}$ to $F_{m}$ dimensionless (no longer used in the 1997 draft standard. included on the attached spread sheets for information)

$r_{g}=$ gas density. $\mathrm{g} / \mathrm{cm}^{3}$ 
7.2.1.2 Basic Flow Equations. Section B3 (Gas Leakage) of ANSI N-14.5 1997J. Appendix B, lists the following equations and describes their application.

(B-1) $Q=L \star P$ atm. $\mathrm{cm}^{3} / \mathrm{s}$ - $A$ mass-7ike flow rate.

$\begin{aligned}(B-2) L_{a}= & \left(F_{c}+F_{m}\right)\left(P_{u}-P_{d}\right) \mathrm{cm}^{3} / \mathrm{s}-\text { - Used to estimate volume leakage rate } \\ & \text { at the average pressure -- where }\end{aligned}$

$(B-3) F_{c}=\left[2.49 \times 10^{6} \times D^{4}\right] /(a \mu) \mathrm{cm}^{3} / a t m . s$ - - and where

$(B-4) F_{m}=\left[3.81 \times 10^{3} \star D^{3} \star(T / M)^{0.5}\right] /\left(a P_{a}\right) \mathrm{cm}^{3} / a t m . s e c$.

$(B-5) L_{u}=\left(F_{c}+F_{m}\right)\left(P_{u}-P_{d}\right)\left(P_{a} / P_{u}\right) \mathrm{cm}^{3} / \mathrm{s} O R L_{d}=\left(F_{c}+F_{m}\right)\left(P_{u}-P_{d}\right)\left(P_{a} / P_{d}\right) \mathrm{cm}^{3} / \mathrm{s}$

used to express leakage rates in terms of upstream or downstream pressure conditions, as opposed to the average stream pressure basis used by equation $(B-2)$.

(B-6) $P_{m}={ }_{j=1} \sum^{n} P_{i}:(B-7) M_{m}=\sum_{j=1} \sum^{n} P_{j} M_{i} / P_{m}:$ and $(B-8) \mu_{m}=\sum_{j=1} \sum^{n} P_{i} \mu_{i} / P_{m}$

-- used to calculate equivalent pressure, molecular weight, and viscosity for ideal gasses in terms of component properties of an $n$ component mixture weighted by the ratio of partial to total pressure.

7.2.1.3 Hand Calculation At Reference Conditions. The left hand column of Table B.2 (Upstream Air Leakage for Various Hole Diameters) of ANSI N-14.5 Draft $1997 \mathrm{~J}$ includes a calculated air leakage rate of $7.94 \times 10^{-5} \mathrm{std} \mathrm{cm}^{3} / \mathrm{s}$. The flow conditions and the leak reporting basis specified for the leak rates listed on the left side of the table were selected to match the standard's definition for the "reference air leakage rate" $\left(L_{R}\right)$ that is the basis for all leak test acceptance criteria under ANSI N-14.5.

The following hand calculation is provided to demonstrate the basic flow equations used to obtain the $7.94 \times 10^{-5} \mathrm{std} \mathrm{cm}^{3} / \mathrm{s}$ flow rate and to validate their implementation in the spread sheet program. The spread sheet listing for this calculation is provided on page 37 (in Appendix $A$ of this document). A11 of the following equation numbers, table numbers. etc., refer to Appendix B of ANSI B-14.5 Draft $1997 \mathrm{~J}$, unless stated otherwise.

\section{Equation B-3}

$F_{\mathrm{c}}=\left[2.49 \times 10^{6} \times D^{4}\right] /(\mathrm{a} \mu) \mathrm{cm}^{3} / \mathrm{atm} . \mathrm{s} \quad$.- where:

$\mathrm{a}=$ hole length $=1 \mathrm{~cm}$ (from Table B.2)

$\mathrm{D}=$ hole diameter $=1 \times 10^{-3} \mathrm{~cm}$ (from Table B.2)

$\mu=$ viscosity of air at $298 \mathrm{~K}\left(25^{\circ} \mathrm{C}\right)=0.0185 \mathrm{cP}$ (from Table B.1)

Note that the $2.49 \times 10^{6}$ multiplier includes the conversion factor to get from centipoise $\left(10^{-2} \mathrm{dyne} . \mathrm{sec} / \mathrm{cm}^{2}\right)$ to atm. sec. Other than to make that observation. this document will not break the conversion factor out of the overa 11 multiplier, nor wi11 it attempt to carry the units. This also applies 
to similar situations with other parameters that occur in subsequent equations. The justification for this approach is that the purpose of this section is to demonstrate that the spread sheet calculations correctly implement the ANSI standard's equations, as opposed to validating the equations themselves.

$$
F_{c}=\left[2.49 \times 10^{6} \times\left(1 \times 10^{-3} \mathrm{~cm}\right)^{4}\right] /(1 \mathrm{~cm})(0.0185 \mathrm{cP})=1.346 \times 10^{-4} \mathrm{~cm}^{3} / \mathrm{atm} . \mathrm{s}
$$

\section{Equation B-4}

$$
\begin{aligned}
& F_{m}=\left[3.81 \times 10^{3} \times D^{3}(T / M)^{0.5}\right] /\left(\mathrm{aP}_{\mathrm{a}}\right) \mathrm{cm}^{3} / \mathrm{atm} . \mathrm{sec} \text {. - where: } \\
& \mathrm{T}=298 \mathrm{~K} \text { (from Table B.2) } \\
& M=29.0 \mathrm{~g} / \mathrm{gmol} \text { (From Table B.1) } \\
& P_{\mathrm{a}}=\text { average stream pressure }=1 / 2\left(P_{\mathrm{u}}+\mathrm{P}_{\mathrm{d}}\right. \text { ) atm abs (from Section B2) } \\
& P_{u}=\text { upstream pressure }=1 \text { atm abs (from Table B.2) } \\
& P_{d}=\text { downstream pressure }=0.01 \mathrm{~atm} \text { abs (from Table B.2) } \\
& F_{m}=\left[3.81 \times 10^{3} \times\left(1 \times 10^{-3} \mathrm{~cm}\right)^{3}(298 \mathrm{~K} / 29.0 \mathrm{~g} / \mathrm{gmol})^{0.5}\right] /\left[\left(1 \mathrm{~cm} \times 1 / 2\left(P_{\mathrm{u}}+\mathrm{P}_{\mathrm{d}}\right)\right]=\right. \\
& {\left[3.81 \times 10^{-6} \times(10.276)^{0.5}\right] /[1 / 2(0.01+1.00)]=\left[3.81 \times 10^{-6} \times 3.206\right] /[0.505]=} \\
& \underline{2.42 \times 10^{-5} \mathrm{~cm}^{3} / \mathrm{atm} . \mathrm{sec}}
\end{aligned}
$$

\section{Equation B-5}

$L_{u}=\left(F_{c}+F_{m}\right)\left(P_{u}-P_{d}\right)\left(P_{a} / P_{u}\right) \mathrm{cm}^{3} / \mathrm{s}$ - - a 11 parameters are 1 isted above.$$
L_{u}=\left(1.346 \times 10^{-4}+2.42 \times 10^{-5}\right)(1.00-0.01)(0.505 / 1.00)=7.94 \times 10^{-5} \mathrm{~cm}^{3} / \mathrm{s}
$$

This result exactly matches the leak rate listed in Table B.2, as does the value for $L_{u}$ in the left hand "Air - Std" column of the spread sheet listing on page 37 of this document (in Appendix A). In order to verify correct implementation of equations B-3, B-4, and B-5 in the calculations for welded MCO's (on the right hand side of each spread sheet 7 isting), a $2 \times 10^{-4}$ $\mathrm{cm}$ hole diameter was input to the spread sheet program. Again. the resulting flow rate for upstream pressure conditions $\left(2.04 \times 10^{-7} \mathrm{~cm}^{3} / \mathrm{s}\right)$ exactly matched that listed by Table B.2 for that hole diameter.

7.2.1.4 Hand Calculation At Test Conditions. This section provides a hand calculation to demonstrate the general approach used to correlate leakage rates between different conditions. The hole diameters that are used for the MCO leak calculations $\left(5.81 \times 10^{-4}\right.$ and $1.63 \times 10^{-4} \mathrm{~cm}$, respectively) were obtained by iterating trial diameters unt 11 the vaTues representing the leak test criteria ( $1 \times 10^{-5}$ and $1 \times 10^{-7} \mathrm{scc} / \mathrm{s}$, respectively) appeared at the top of the two "Air ( $L r$ )" columns on pages 38 and 39 (in Appendix A). Once those were obtained, the spread sheet calculation used these hole diameters to obtain the values at the top of the "He - Test" columns, which predict the helium leak rates that would be observed at the anticipated leak testing conditions that correspond to the reference criteria. In this case, the only difference in conditions is the use of helium instead of air. 
Section B4 (Correlation Between Gas Leakage Rates at Different Conditions) of ANSI B-14.5 Draft $1997 \mathrm{~J}$ states (in sub-section B4.1): "Using Equation B-2 or Equation B-5. the leakage hole diameter is found for the known conditions. Leakage is found at other conditions using the calculated diameter. Equation B-2 or Equation B-5, and the specified conditions." Consequently, the correlation between the reference leak $\left(L_{R}\right)$ and the measured helium leak test flow is performed by simply substituting helium parameters for those of air in the previous calculations (see section 7.2.1.3).

Equation B-3

$$
\begin{aligned}
& F_{c}=\left[2.49 \times 10^{6} \times D^{4}\right] /(a \mu) \mathrm{cm}^{3} / a t m . s \quad \text {-. where: } \\
& \mathrm{a}=\text { hole length }=1 \mathrm{~cm}(\text { from Table B.2) } \\
& \mathrm{D}=\text { hole diameter }=5.81 \times 10^{-4} \mathrm{~cm} \text { (see above) } \\
& \mu=\text { viscosity of helium at } 298 \mathrm{~K}\left(25^{\circ} \mathrm{C}\right)=0.0198 \mathrm{cP} \text { (from Table B.1) } \\
& F_{c}=\left[2.49 \times 10^{6} \times\left(5.81 \times 10^{-4} \mathrm{~cm}\right)^{4}\right] /(1 \mathrm{~cm})(0.0198 \mathrm{cP})=\underline{1.43 \times 10^{-5} \mathrm{~cm}^{3} / \mathrm{atm} . \mathrm{S}}
\end{aligned}
$$

Equation B-4

$F_{m}=\left[3.81 \times 10^{3} \times D^{3}(T / M)^{0.5}\right] /\left(a P_{\jmath}\right) \mathrm{cm}^{3} / a$ atm. sec. - where:

$T=298 \mathrm{~K}$ (from Table B.2)

$M=4.0 \mathrm{~g} / \mathrm{gmol}$ (From Table B.1)

$P_{\mathrm{d}}=$ average stream pressure $=1 / 2\left(P_{\mathrm{u}}+\mathrm{P}_{\mathrm{d}}\right)$ atm abs (from Section B2)

$P_{\mathrm{u}}=$ upstream pressure $=1 \mathrm{~atm}$ abs (from Table B.2)

$P_{d}=$ downstream pressure $=0.01 \mathrm{~atm}$ abs (from Table B.2)

$F_{m}=\left[3.81 \times 10^{3} \times\left(5.81 \times 10^{-4} \mathrm{~cm}\right)^{3}(298 \mathrm{~K} / 4.0 \mathrm{~g} / \mathrm{gmo} 7)^{0.5}\right] /\left[\left(1 \mathrm{~cm} \times 1 / 2\left(\mathrm{P}_{\mathrm{u}}+\mathrm{P}_{\mathrm{d}}\right)\right]=\right.$ $\left[3.81 \times 10^{3} \times 1.96 \times 10^{-10} \times(74.5)^{0.5}\right] /[1 / 2(0.01+1.00)]=$

$$
\left[7.5 \times 10^{-7} \times 8.63\right] /[0.505]=1.28 \times 10^{-5} \mathrm{~cm}^{3} / \mathrm{atm} . \mathrm{sec}
$$

\section{Equation B-5}

$$
\begin{aligned}
& L_{u}=\left(F_{c}+F_{m}\right)\left(P_{u}-P_{d}\right)\left(P_{a} / P_{u}\right) \mathrm{cm}^{3} / \mathrm{s} \cdots \text { all parameters are listed above. } \\
& L_{u}=\left(1.43 \times 10^{-5}+1.28 \times 10^{-5}\right)(1.00-0.01)(0.505 / 1.00)=1.36 \times 10^{-5} \mathrm{~cm}^{3} / \mathrm{s}
\end{aligned}
$$

This result matches the value for $L_{u}$ in the "He-Test" column on the left side of the spread sheet listing on pages 38 and 39 of this document. The hand calculation for the helium rate at the maximum acceptance criterion for a welded seal $\left(1 \times 10^{-7} \mathrm{scc} / \mathrm{s}\right)$ would be identical, other than for the smaller hole size.

Notice that the increase in calculated flow rate upon substitution of 
helium for air is only about one third of the generally accepted rule of thumb. which holds that the helium flow rate will be about twice that of the air flow rate. That discrepancy does not, however, mean that the above calculations are in error. For conditions that lead to calculated air flows above $10^{-7} \mathrm{~cm}^{3} / \mathrm{s}$. the validity of the rule decreases as the air flow increases. Consequently, there is very little difference between the calculated flow rates for air and helium in the $10^{-5}$ std $\mathrm{cm}^{3} / \mathrm{s}$ range. The reason for this is that continuum flow dominates in that region $\left(F_{c} / F_{m}=3.2\right.$ for air, and 1.1 for helium), whereas the rule of thumb applies to flow on the order of $10^{-7} \mathrm{~cm}^{3} / \mathrm{s}$ or less, where free molecular flow begins to dominate. This trend is apparent on consideration of the flow rates calculated for air $\left(1.0 \times 10^{-7} \mathrm{~cm}^{3} / \mathrm{s}\right)$ and helium $\left(1.86 \times 10^{-7} \mathrm{~cm}^{3} / \mathrm{s}\right)$ that appear on the right side of the spread sheet listing, where the hel ium flow rate is about 1.9 times the air flow rate. At these conditions the helium flow is plainly in the free molecular regime $\left(F_{c} / F_{m}=0.32\right)$ and air flow is split about evenly between them $\left(F_{c} / F_{m}=0.91\right)$.

7.2.1.5 Hand Calculation At Operating Conditions. The calculations required to predict leak rates for mixtures of gases at anticipated worst case operating conditions are more complex than those demonstrated in sections 7.2.1.3 and 7.2.1.4. which involved single component gases at essentially ambient conditions. None the less, the basic approach is unchanged from that out lined by section B4.1 of ANSI B-14.5 Draft $1997 \mathrm{~J}$ (see section 7.2.1.4). The primary difference is that it is necessary to calculate composite gas properties for the mixture using equation B-6. See Appendix A of this document for the spread sheet listing that was used [by iterating hole diameters against resulting values for $L_{u}$ ] to establish the equivalent singlehole diameter $\left(5.81 \times 10^{-4} \mathrm{~cm}\right)$ that would result in the specified maximum standard leak test result $\left(1 \times 10^{-5} \mathrm{scc} / \mathrm{s}\right)$. The spread sheet listings then go on to duplicate and summarize the hand calculations of sections 7.2.1.5.1 and 7.2.1.5.2 below.

\subsection{Helium Loss Calculations.}

Minimum Heljum Inventory Case From Section 7.1.2.1

- Hydrogen (maximum safety basis inventory) -....... 65.5 gmol

- Backfil gas (Minimum Helium Inventory) -......... 31.9 gmol

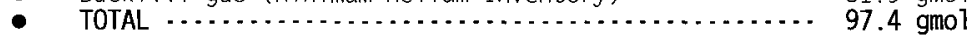

Calculation of Effective Molecular Weight for Gas Mixture

$$
\begin{aligned}
& \text { (B-6) } P_{m}=i_{i=1} \sum^{n} P_{i} \text {; but }\left(P_{i} / P_{m}\right)=\left(\text { gmol component }_{i} / \text { gmol mixture } \text { com }_{m}=\text { mol }- \text { frac }_{i}\right. \\
& \text { (B-7) } M_{m}=\sum_{i=1} \sum^{n} P_{i} M_{i} / P_{m} \text {; from equation } B-6 . M_{m}=\sum_{i=1}^{n} m_{01}^{n}-\operatorname{frac}_{i} M_{i} \\
& \text { Mol-frac } \mathrm{H}_{2}=65.5 \mathrm{gmol} / 97.4 \mathrm{gmol}=0.6725 \text {; and } M_{\text {hydrogen }}=2 \mathrm{~g} / \mathrm{gmol} \\
& \text { Mol-frac } H_{e}=31.9 \text { gmol } / 97.4 \text { gmol }=0.3275 ; \text { and } M_{\text {helium }}=4 \mathrm{~g} / \mathrm{gmol} \\
& M_{\mathrm{m}}=0.6725 \times 2 \mathrm{~g} / \mathrm{gmol}+0.3275 \times 4 \mathrm{~g} / \mathrm{gmol}=1.345 \mathrm{~g} / \mathrm{gmol}+1.310 \mathrm{~g} / \mathrm{gmol} \\
& =\underline{2.66 \mathrm{~g} / \mathrm{gmol}}
\end{aligned}
$$


Calculation of Effective Viscosity for Gas Mixture

(B-8) $\mu_{m}={ }_{j=1} \sum^{n} P_{i} \mu_{i} / P_{m}$; from equation B-6. $\mu_{m}=\sum_{i=1} \sum^{n}$ mol-frac $\mu_{i} \mu_{i}$

Mol-frac $\mathrm{H}_{2}=0.6725$; and $\mu_{\text {hydrogen }}$ a $337 \mathrm{~K}=0.0096 \mathrm{cP}$

Mol-frac $H_{e}=0.3275$; and $\mu_{\text {helium }}$ a $337 \mathrm{~K}=0.0212 \mathrm{CP}$

$\mu_{\mathrm{m}}=0.6725 \times 0.0096 \mathrm{cP}+0.3275 \times 0.0212 \mathrm{cP}=$

$0.00646+0.00694=\underline{0.0134 C P}$

Calculation of Leak Rate for Gas Mixture

$(B-3) \mathrm{F}_{\mathrm{c}}=\left[2.49 \times 10^{6} \times D^{4}\right] /(\mathrm{a} \mu) \mathrm{cm}^{3} /$ atm. $\mathrm{s} \quad$ - where:

$\mathrm{a}=$ hole length $=1 \mathrm{~cm}$ (from Table B.2)

$D=$ hole diameter $=5.81 \times 10^{-4} \mathrm{~cm}$

Note -- The hole diameter $(D)$ is obtained by iterating the hole size against the upstream flow rate $\left(\mathrm{L}_{\mathrm{u}}\right)$ in the first column of the spread sheet listed on page 38 of this document. The final value used for $D$ corresponds to the diameter that results in the specified leak test criterion $\left(1 \times 10^{-5} \mathrm{scc} / \mathrm{s}\right.$ in this case $)$.

$\mu_{\mathrm{m}}=$ viscosity of gas mixture at $337 \mathrm{~K}=0.0134 \mathrm{cP}$

$F_{c}=\left[2.49 \times 10^{6} \times\left(5.81 \times 10^{-4} \mathrm{~cm}\right)^{4}\right] /(1 \mathrm{~cm})(0.0134 \mathrm{cP})=$

$\left[2.49 \times 10^{6} \times\left(1.14 \times 10^{-13}\right)\right] / 0.0134=2.837 \times 10^{-7} / 0.0134=$

$2.12 \times 10^{-5} \mathrm{~cm}^{3} / \mathrm{atm} . \mathrm{s}$

$(B-4) F_{m}=\left[3.81 \times 10^{3} \times D^{3}(T / M)^{0.5}\right] /\left(\mathrm{aP}_{\mathfrak{a}}\right) \mathrm{cm}^{3} /$ atm.sec. - where:

$T=337 \mathrm{~K}$ (from section 4.4 )

$M_{m}=2.66 \mathrm{~g} / \mathrm{gmol}$

$P_{u}=5.4$ atm abs (from section 7.1.3.1)

$P_{d}=1 \mathrm{~atm}$ abs (MCO leaks are to ambient or near-ambient pressure)

$P_{a}=1 / 2\left(P_{u}+P_{d}\right) a t m a b s=1 / 2(5.4+1) \mathrm{atm} a b s=3.2 \mathrm{~atm} \mathrm{abs}$

$F_{\mathrm{m}}=\left[3.81 \times 10^{3} \times\left(5.81 \times 10^{-4} \mathrm{~cm}\right)^{3}(337 \mathrm{~K} / 2.66 \mathrm{~g} / \mathrm{gmo} 1)^{0.5}\right] /[(1 \mathrm{~cm} \times 3.2 \mathrm{~atm}]=$

$\left[\left(3.81 \times 10^{3}\right)\left(1.961 \times 10^{-10}\right)(126.7)^{0.5}\right] / 3.2=\left(7.47 \times 10^{-7}\right)(11.26) / 3.2=$

$2.63 \times 10^{-6} \mathrm{~cm}^{3} / \mathrm{atm} . \mathrm{sec}$ 
(B-5) $\mathrm{L}_{\mathrm{u}(\mathrm{m} / \mathrm{x})}=\left(\mathrm{F}_{\mathrm{c}}+\mathrm{F}_{\mathrm{m}}\right)\left(\mathrm{P}_{\mathrm{u}}-\mathrm{P}_{\mathrm{d}}\right)\left(\mathrm{P}_{\mathrm{a}} / \mathrm{P}_{\mathrm{u}}\right) \mathrm{cm}^{3} / \mathrm{s}$ - - all parameters are listed above.

$L_{u(\text { mix })}=\left(2.12 \times 10^{-5}+2.63 \times 10^{-6}\right)(5.4-1.0)(3.2 / 5.4)=$

$\left(2.38 \times 10^{-5} \mathrm{~cm}^{3} / \mathrm{atm} . \mathrm{sec}\right)(4.4)(0.593)=\underline{6.21 \times 10^{-5} \mathrm{~cm}^{3} / \mathrm{s}}$

\section{Calculation of Leak Rate for the Helium Component of Gas Mixture}

From the above calculation: $F_{1}=2.12 \times 10^{-5} \mathrm{~cm}^{3} /$ atm. $s$ and $F_{\mathrm{m}}=2.63 \times 10^{-6} \mathrm{~cm}^{3} / \mathrm{atm} . \mathrm{sec}\left(.263 \times 10^{-5} \mathrm{~cm} / \mathrm{atm} . \mathrm{s}\right)$, such that $F_{\mathrm{c}} / F_{\mathrm{m}}=8.1$, which is to say that continuum flow dominates. This. in turn. means that the mole fraction of helium on the downstream side of the leak will be essentially identical to its mole fraction on the upstream side. To put it another way. the helium will simply be swept out of the MCO by the leaking gas mixture:

$$
L_{u(\text { hel ium) }}=L_{u(\text { (mix) }} \times \text { mole-frac } \mathrm{He}_{\text {He }}=6.21 \times 10^{-5} \mathrm{~cm}^{3} / \mathrm{s} \times 0.3275=\underline{2.03 \times 10^{-5} \mathrm{~cm}^{3} / \mathrm{s}}
$$

For helium, the issue is time to minimum acceptable inventory. consequently the result is expressed as gmol of helium lost per unit of time via $P V=n R T$, or $n=P V / R T$ :

$$
\begin{aligned}
& P_{u}=5.4 \mathrm{~atm} \text { abs } \\
& T_{u}=337 \mathrm{~K} \\
& \mathrm{R}=0.082 \mathrm{~L} . \mathrm{atm} / \mathrm{gmol} . \mathrm{K} \\
& \mathrm{L}_{\text {He(molar })}=\left(\mathrm{L}_{\text {He(volumetric })}\right)(5.4 \mathrm{~atm}) /[(0.082 \mathrm{~L} . \mathrm{atm} / \mathrm{gmol} \mathrm{K})(337 \mathrm{~K})]= \\
&\left(2.03 \times 10^{-5} \mathrm{~cm}^{3} / \mathrm{s}\right)\left(0.001 \mathrm{~L} / \mathrm{cm}^{3}\right)(5.4 \mathrm{~atm}) /[27.63 \mathrm{~L} . \mathrm{atm} / \mathrm{gmol}]= \\
& 3.97 \times 10^{-9} \mathrm{gmol} / \mathrm{sec}=3.43 \times 10^{-4} \mathrm{gmol} / \text { day }=\underline{0.125 \mathrm{gmol} / \text { year }}
\end{aligned}
$$

\subsection{Hydrogen Release Calculations.}

Worst Case Gas Inventory For Hydrogen Release From Section 7.1.2.2

- Hydrogen -- 65.5 gmol

- Backfill gas (maximum fill quantity of He) -...-. 41.3 gmol

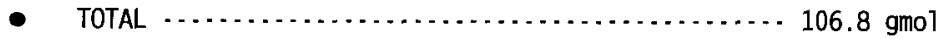


Calculation of Effective Molecular Weight for Gas Mixture

$(B-6) P_{m}=\sum_{j=1} \sum^{n} P_{i}$; where $\left(P_{i} / P_{m}\right)=$ mol-frac

(B-7) $M_{m}={ }_{j=1} \sum^{n} P_{i} M_{i} / P_{m}$; from equation $B-6, M_{m}={ }_{j=1} \sum^{n}$ mol-frac $M_{i}$

Mol-frac $H_{2}=65.5 \mathrm{gmol} / 106.8 \mathrm{gmol}=0.6133$; and $M_{\text {hydrogen }}=2 \mathrm{~g} / \mathrm{gmol}$

Mol-frac $H_{e}=41.3 \mathrm{gmol} / 106.8 \mathrm{gmol}=0.3867$; and $M_{\text {hel um }}=4 \mathrm{~g} / \mathrm{gmol}$

$M_{\mathrm{m}}=0.6133 \times 2 \mathrm{~g} / \mathrm{gmol}+0.3867 \times 4 \mathrm{~g} / \mathrm{gmol}=$

$1.227 \mathrm{~g} / \mathrm{gmol}+1.547 \mathrm{~g} / \mathrm{gmol}=\underline{2.77 \mathrm{~g} / \mathrm{gmol}}$

\section{Calculation of Effective Viscosity for Gas Mixture}

(B-8) $\mu_{\mathrm{m}}={ }_{j=1} \sum^{n} P_{\mu_{1}} / P_{m}$; from equation $B-6, \mu_{m}={ }_{j=1} \sum^{n}$ mol-frac $_{1} \mu_{j}$

Mol-frac $\mathrm{H}_{2}=0.6133$; and $\mu_{\text {hydrogen }}$ a $337 \mathrm{~K}=0.0096 \mathrm{cP}$

Mol-frac $H_{e}=0.3867$; and $\mu_{\text {helium }}$ a $337 \mathrm{~K}=0.0212 \mathrm{cP}$

$\mu_{\mathrm{m}}=0.6033 \times 0.0096 \mathrm{cP}+0.3867 \times 0.0212 \mathrm{cP}=$

$0.00589+0.00820=\underline{0.01409 C P}$

\section{Calculation of Leak Rate for Gas Mixture}

$(B-3) F_{c}=\left[2.49 \times 10^{6} \times 0^{4}\right] /(a \mu) \mathrm{cm}^{3} / a t m . s \quad--$ where:

$a=$ hole length $=1 \mathrm{~cm}$ (from Table B.2)

$D=$ hole diameter $=5.81 \times 10^{-4} \mathrm{~cm}$

Note -- The hole diameter (D) is obtained by iterating the hole size against the upstream flow rate $\left(L_{u}\right)$ in the first column of the spread sheet 7 isted on page 39 of this document. The final value used for $D$ corresponds to the diameter that results in the specified leak test criterion $\left(1 \times 10^{-5} \mathrm{scc} / \mathrm{s}\right.$ in this case $)$.

$\mu_{\mathrm{m}}=$ viscosity of gas mixture at $337 \mathrm{~K}=0.0141 \mathrm{cP}$

$F_{c}=\left[2.49 \times 10^{6} \times\left(5.81 \times 10^{-4} \mathrm{~cm}\right)^{4}\right] /(1 \mathrm{~cm})(0.0141 \mathrm{cP})=$ $\underline{2.012 \times 10^{-5} \mathrm{~cm}^{3} / \mathrm{atm} . \mathrm{s}}$ 
(B-4) $\mathrm{F}_{\mathrm{m}}=\left[3.81 \times 10^{3} \times \mathrm{D}^{3}(\mathrm{~T} / \mathrm{M})^{0.5}\right] /\left(\mathrm{aP}_{\mathrm{a}}\right) \mathrm{cm}^{3} / \mathrm{atm} . \mathrm{sec}$, - - where:

$T=337 \mathrm{~K}$ (from section 4.4)

$M_{\mathrm{m}}=2.77 \mathrm{~g} / \mathrm{gmo} 7$

$P_{u}^{\text {mu }}=5.9 \mathrm{~atm}$ abs (from section 7.1.3.2)

$P_{d}=1 \mathrm{~atm}$ abs (MCO leaks are to ambient or near-ambient pressure)

$P_{a}=1 / 2\left(P_{u}+P_{d}\right)$ atm abs $=1 / 2(5.9+1)$ atm abs $=3.45$ atm abs

$\left.F_{\mathrm{m}}=\left[3.81 \times 10^{3} \times\left(5.81 \times 10^{-4} \mathrm{~cm}\right)^{3}(337 \mathrm{~K} / 2.77 \mathrm{~g} / \mathrm{gmo})\right)^{0.5}\right] /[(1 \mathrm{~cm} \times 3.45 \mathrm{~atm}]=$

$\left[7.47 \times 10^{-7} \times(121.7)^{0.5}\right] / 3.45=\left[7.47 \times 10^{-7} \times 11.03\right] / 3.45=$

$2.39 \times 10^{-6} \mathrm{~cm}^{3} / \mathrm{atm} . \mathrm{sec}$

(B-5) $L_{u(m \mid x)}=\left(F_{c}+F_{m}\right)\left(P_{u}-P_{d}\right)\left(P_{a} / P_{u}\right) \mathrm{cm}^{3} / s--a 11$ parameters are 1isted above.

$L_{u(\text { mix })}=\left(2.012 \times 10^{-5}+2.39 \times 10^{-6}\right)(5.9-1.0)(3.45 / 5.9)=$

$\left(2.25 \times 10^{-5}\right)(4.9)(0.585)=\underline{6.45 \times 10^{-5} \mathrm{~cm}^{3} / \mathrm{s}}$

\section{Calculation of Leak Rate for the Hydrogen Component of Gas Mixture}

From the above calculation: $F_{F}=2.012 \times 10^{-5} \mathrm{~cm}^{3} / a t m . s$, and $F_{m}=2.39 \times 10^{-5} \mathrm{~cm}^{3} / \mathrm{atm} . \mathrm{sec}\left(0.239 \times 10^{-5} \mathrm{~cm}^{3} / \mathrm{atm} . \mathrm{s}\right)$, such that $F_{c}^{m} / F_{m}=8.42$ (i.e.. continuum flow dominates). Consequently the hydrogen is simply swept out with the overall flow as a component of the gas mixture (see section 7.2.1.5.1):

$$
L_{u}=L_{u(\operatorname{mix})} \times \text { mole-frac hydrogen }=6.45 \times 10^{-5} \mathrm{~cm}^{3} / \mathrm{s} \times 0.613=3.95 \times 10^{-5} \mathrm{~cm}^{3} / \mathrm{s}
$$

For hydrogen. the issue is time to maximum acceptable hydrogen concentration in a CSB storage tube, consequently the result can either be expressed as gmol of hydrogen released to the tube per unit of time. or as volumetric flow rate at the downstream pressure $\left(L_{d}\right)$ and temperature $\left(T_{d}\right)$. The spread sheet calculations include both values. Regardless of whether the flow is expressed in moles or liters, the calculation for time to reach the maximum hydrogen concentration limit requires that either the volumetric flow rate from the $\mathrm{MCO}$ or the molar contents of the tube be corrected to the worst case (maximum) gas temperature within the tube $\left(T_{d}\right)$. For the purposes of this document, that temperature is conservatively taken as the upstream gas temperature $\left(64^{\circ} \mathrm{C}--337 \mathrm{~K}\right)$ per section 4.4 .

$$
\begin{aligned}
& \text { (B-5) } L_{d(m i \mathrm{x})}=\left(F_{c}+F_{m}\right)\left(P_{u}-P_{d}\right)\left(P_{d} / P_{d}\right)=\left(2.25 \times 10^{-5}\right)(4.9)(3.45 / 1)= \\
& \quad 38.04 \times 10^{-5} \mathrm{~cm}^{3} / \mathrm{s}=3.80 \times 10^{-4} \mathrm{~cm}^{3} / \mathrm{s} \text { at } 337 \mathrm{~K} \\
& \text { Based on the above, the hydrogen flow is: } \\
& L_{d}=L_{d(m i x)} \times \text { mole-frac } C_{\text {hydrogen }}=3.80 \times 10^{-4} \mathrm{~cm}^{3} / \mathrm{s} \times 0.613=2.33 \times 10^{-4} \mathrm{~cm}^{3} / \mathrm{s} .
\end{aligned}
$$


HNF-2155 Rev 1

\subsection{MAXIMUM STEADY STATE HYDROGEN CONCENTRATION IN CSB TUBES}

The hydrogen release calculations summarized by the spread sheet listing on page 39 of this document conclude that it would take almost a year for the hydrogen concentration to reach 1 v01\% within a sealed CSB tube containing two safety basis pressure, mechanicaT7y sealed MCOs. However, the current CSB design provides vented tube closures for all air-atmosphere tubes. This section documents the ability of the stagnant vent paths to limit steady state hydrogen concentrations within CSB tubes to acceptable levels. The goal is to demonstrate that the hydrogen concentration within a worst case tube will never exceed 1 vol\% hydrogen (25\% of the LFL).

\subsubsection{DiTution by Barometrically Induced Breathing}

This section calculates the worst case steady state hydrogen concentration that is ever expected to occur within any CSB tube, based on dilution of hydrogen within tubes as a result of "tube breathing" driven by barometric pressure variations alone. Breathing calculations are limited to barometric effects because thermal cycling within the CSB vault is not considered to be reliable for this purpose (there is no guarantee that all tubes would be subject to it).

7.3.1.1 Assumptions. The breathing calculations assume that, even in the case where a particular storage tube payload provides little or no heat to support a vertical thermal gradient within the tube, the air within that storage tube wi 11 be well mixed. This assumption is reasonable in view of the long time frame required for a completely sealed tube to reach 1 vol\% hydrogen (over ten months).

These calculations also assume that the difference between the observed 1.69 atmosphere integrated annual barometric pressure variation (see section 7.3.1.2) and the more conservative value used for this calculation (1.25 atmospheres) is sufficient to compensate for (among other things) volumetric hold-up within the vent paths, which is calculated to require a 0.01 " $\mathrm{Hg}$ minimum sustained change (up or down) before any subsequent change wi11 result in a net movement of air to or from the storage tube (see the second paragraph of section 7.3.1.2).

7.3.1.2 Basis For Air-Exchange Rate. Local barometric effects have most recently been documented in Barometric Pressure Variations (WHC-EP-0651), which reports an integrated annual barometric pressure variation of 1.69 atmospheres (i.e.. tube volumes). Table 6 of that report provides minimum, average, and maximum integrated short-term data for periods from one hour to one year. While daily pressure swings can approach zero for several consecutive days, the minimum value is within $75 \%$ of the average value for periods on the order of one month or more. For time periods on the order of one year, the minimum value is within $99 \%$ of the average value. In view of the fact that the worst case calculation in this document predicts that a completely sealed tube would not reach 1 vol\% hydrogen during the first ten months of service, it should be sufficiently conservative to base a "breathing allowance" for vented tubes on a value that Table 6 [of WHC-EP-0651] describes as the minimum integrated pressure swing over a period of one month or less. That table lists the minimum integrated swing as 2.97 inches of mercury over a 
696 hour period (less than one month), which is equivalent to 0.00427 inches of mercury per hour, or 37.38 inches of mercury per year. At 29.92 inchs of mercury per atmosphere, this translates to $37.38 / 29.92$, or 1.25 atmospheres per year.

Finally, consideration must be given to the effects of hold-up within the tube's shield plug vent ports. The shield plug is provided with two identical vent ports, each of which consists of a 9" long 3/4" I.D. hole bored into the side of the shield plug at its upper end, and slanting upward to a point where it intersects a 2" deep vertical hole that has been bored into the upper face of the shield plug. The vertical hole is taped to receive a $21 / 2$ " long, 3/4" NPT pipe nipple. The vent port terminates with a 3/4" NPT pipe coupling and a sma11 strainer fitting (the "breather vent assembly"). Based on a $170 \mathrm{~cm}^{3}$ estimate for the hold-up volume of each assembly, a total hold-up volume of $0.4 \mathrm{~L}$ should be conservative (see section 4.7 for the volume calculations). Given a total net storage tube void volume of $1300 \mathrm{~L}$ for the worst case payload configuration (again, see section 4.7 ), the $0.4 \mathrm{~L}$ hold-up volume represents only about three hundredths of $1 \%\left(3.1 \times 10^{-4}\right)$ of the worst case minimum tube volume. Consequent1y, a sustained barometric swing of 0.01 inches of $\mathrm{Hg}$ should be more than adequate to clear the ports of their $0.4 \mathrm{~L}$ hold-up volume and, thereby, allow any subsequent sustained swing (in either direction) to actually transfer gas to or from the storage tube:

$29.92 " \mathrm{Hg}$ (equivalent to one tube volume) $\times 3.1 \times 10^{-4}=0.0093 " \mathrm{Hg}$.

Based on all of the above, it should be both reasonable and conservative to assume that the air within vented CSB tubes will be exchanged at least 1.25 times per year. and that at least $10 \%$ of it will be exchanged per month, on average. And while it is possible that several days may go by without any exchange occurring, the calculated worst case daily hydrogen leakage is so low that any short term interruptions will not result in a significant short term hydrogen build up.

7.3.1.3 Material Balance Equations. Based on a worst case minimum net void volume of $1300 \mathrm{~L}$ for a CSB tube containing two mechanically sealed MCOs (see section 4.7), and based on a worst case maximum hydrogen release rate of $7.31 \times 10^{-4}$ gmol/day per MCO (see the spread sheet listing on page 39 of this document), the following material balance equations apply: 


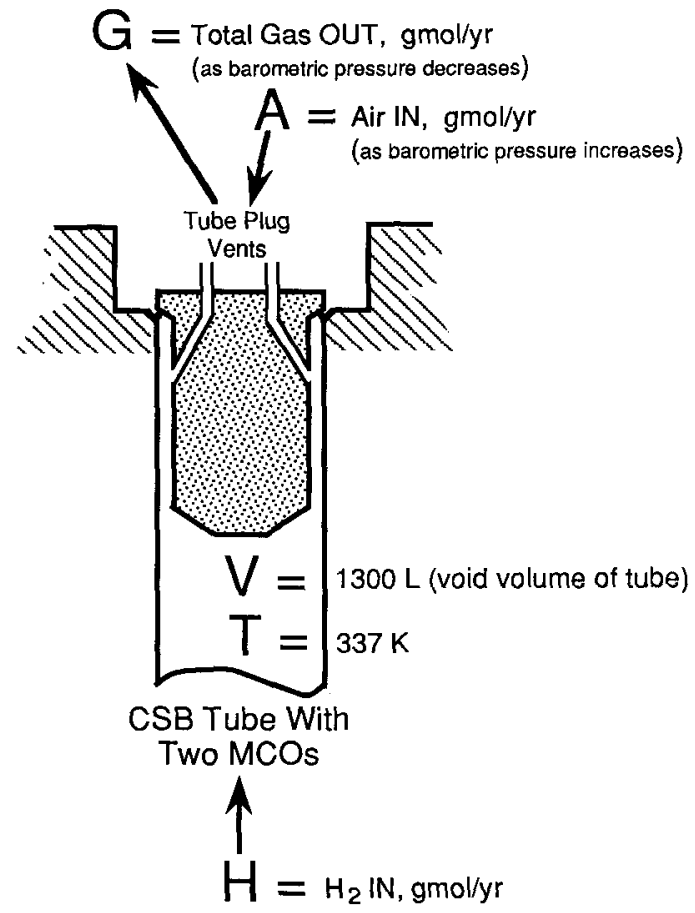

Figure 7-1: Gas Exchange Through CSB Tube Plug Vents

$\mathrm{H}=\mathrm{H}_{2}$ IN $=2\left(7.31 \times 10^{-4} \mathrm{gmo} / \mathrm{day}\right)(365 \mathrm{day} / \mathrm{yr})=0.533 \mathrm{gmol} / \mathrm{yr}$ (see spread sheet listing on page 39 of this document)

$V=1300 \mathrm{~L}$ (see section 4.7 )

$T=337 K$ (see section 4.4$)$

$\mathrm{N}=\mathrm{PV} / \mathrm{RT}=(1 \mathrm{~atm})(1300 \mathrm{~L}) /(.082 \mathrm{~atm} . \mathrm{L} / \mathrm{gmol} . \mathrm{K})(337 \mathrm{~K})=47.0 \mathrm{gmol}$

$A=A i r$ IN (gmol/yr) as barometric pressure increases

$\mathbf{G}=$ Total gas OUT (gmol/yr) as barometric pressure decreases

Given a 1.25 atm annual integrated pressure variation,

$$
G=1.25 \mathrm{~N} / \mathrm{yr}=58.8 \mathrm{gmo} / \mathrm{yr}
$$


Hydrogen Balance

In:

H. gmol $\mathrm{H}_{2} / \mathrm{yr}$

Out: $Y_{H} G$ gmol $H_{2} / y r-Y_{H}=$ mole fraction $H_{2}, G=$ gmol/yr total

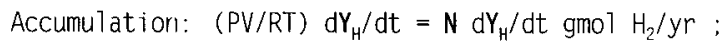

$$
\begin{aligned}
& \mathrm{N} \mathrm{dY}_{\mathrm{H}} / \mathrm{dt}=\mathrm{H}-\left(\mathrm{Y}_{\mathrm{H}} \mathrm{G}\right) ; \\
& \mathrm{dY}_{\mathrm{H}} / \mathrm{dt}+(\mathrm{G} / \mathrm{N}) \mathrm{Y}_{\mathrm{H}}=\mathrm{H} / \mathrm{N} ;
\end{aligned}
$$

The "integrating factor" $\mu=e^{\int G / N d t}=e^{G / N t}$;

$$
e^{G / N t} \times\left[d Y_{H} / d t+(G / N) Y_{H}\right]=(H / N) \times e^{G / N t} ;
$$

$\int d\left(Y_{H} e^{G / N t}\right)=\int H / N e^{G / N t} d t:$

$Y_{H} e^{G / N t}=H / N(N / G) e^{G / N t}+C$ :

$Y_{H}=(N / G)+C e^{-G / N t} ;$

a $t=0, Y_{H}=Y_{H}{ }^{0}$;

$Y_{H}{ }^{0}=(H / G)+C, C=Y_{H}^{0}-(H / G) ;$

$Y_{H}=(H / G)+\left[Y_{H}{ }^{0}-(H / G) e^{-G / N t}\right]=\left[Y_{H}{ }^{0} e^{-G / N t}+\left(1-e^{-G / N ~ t}\right) H / G\right] ;$

As $t$ approaches infinity, $Y_{H}$ approaches $H / G$;

\section{Steady State Solution}

$H=0.533$ gmol $\mathrm{H}_{2} / \mathrm{yr}$ (see above);

$\mathrm{N}=47.0$ gmol (see above);

$\mathrm{G}=58.8 \mathrm{gmol} / \mathrm{yr}$ (see above);

At steady state, $Y_{H}=H / G=(0.533 \mathrm{gmol} / \mathrm{yr}) /(58.8 \mathrm{gmol} / \mathrm{yr})=$

0.0091 . or 0.9 vol\% 


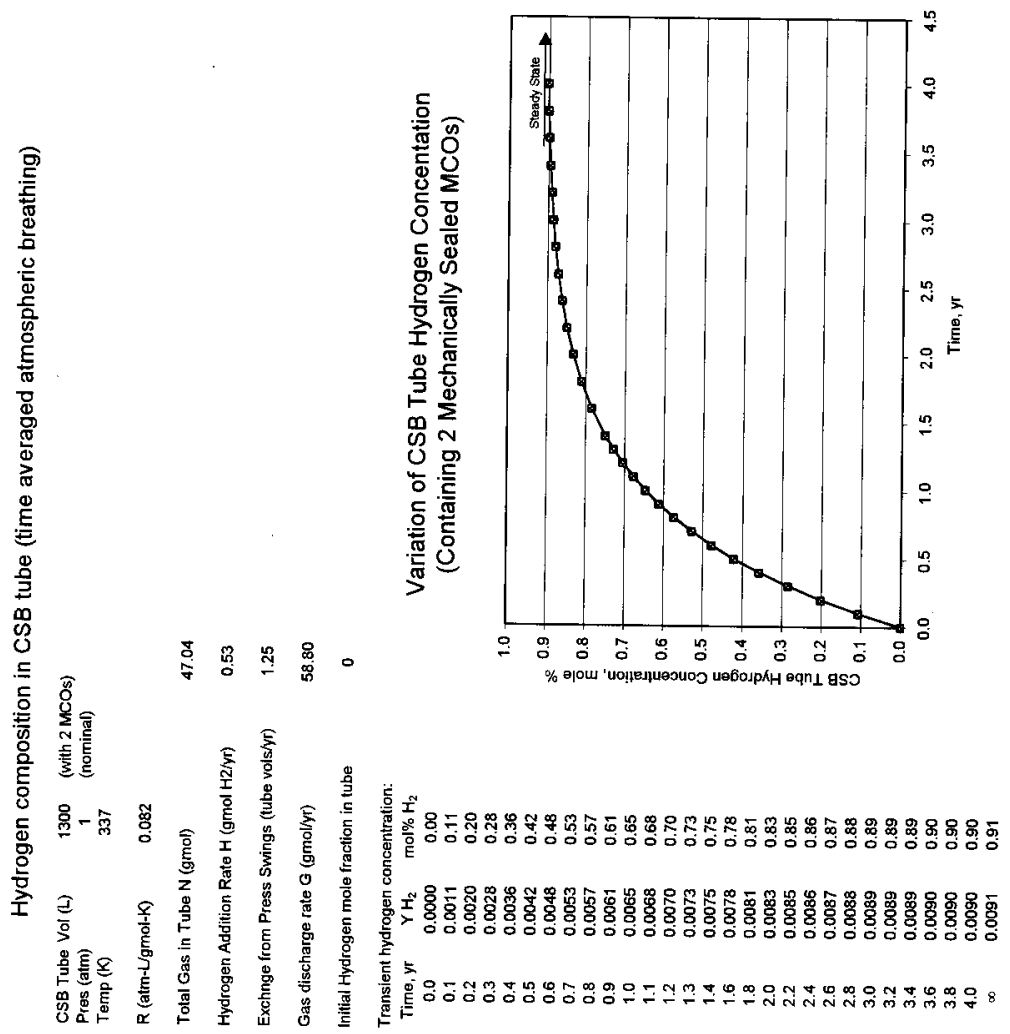

Figure 7-2: Worst Case $\mathrm{H}_{2}$ Concentration With Atmospheric Breathing 
HNF-2155 Rev 1

APPENDIX A: SPREAD SHEET CALCULATIONS 


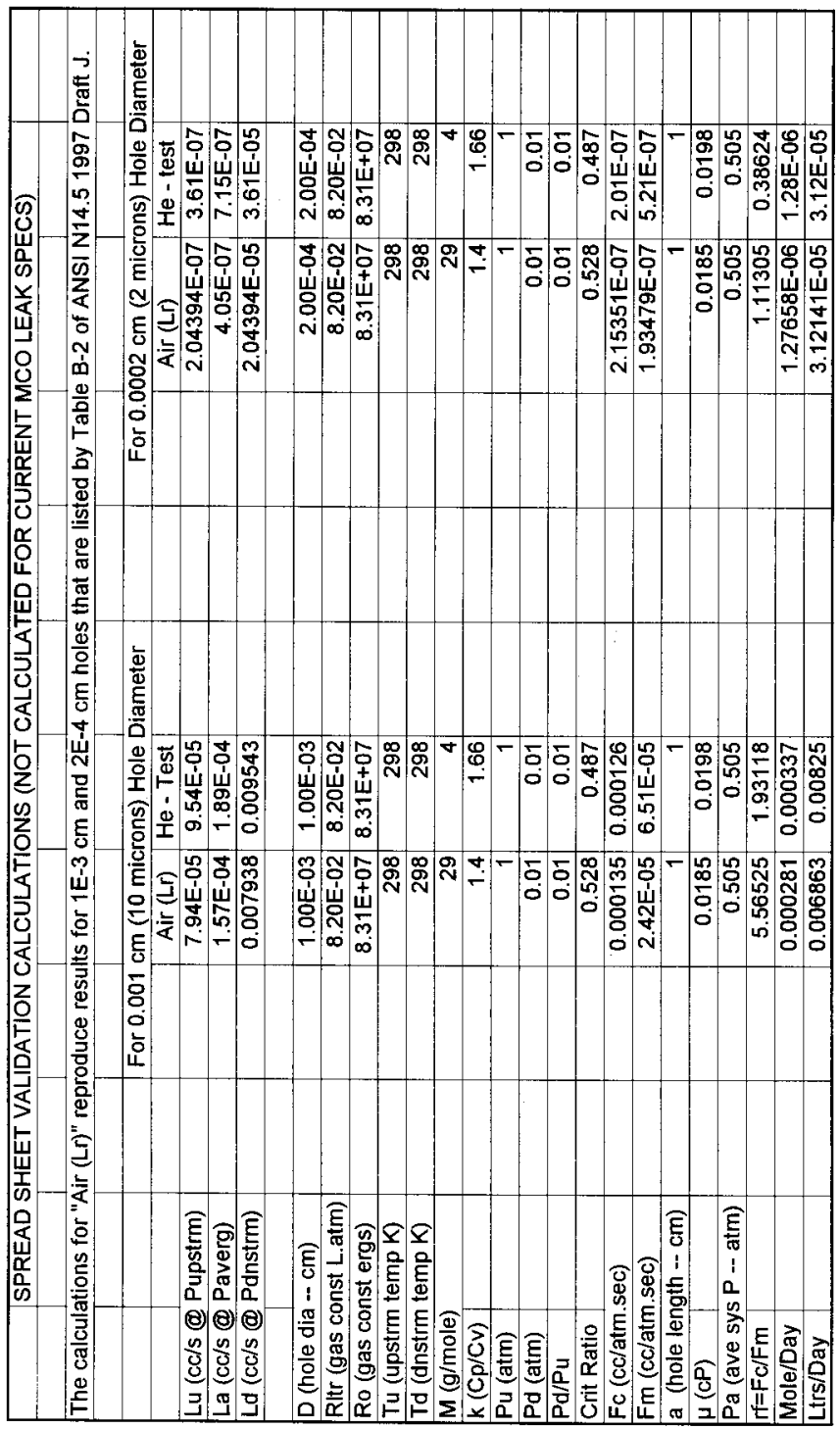




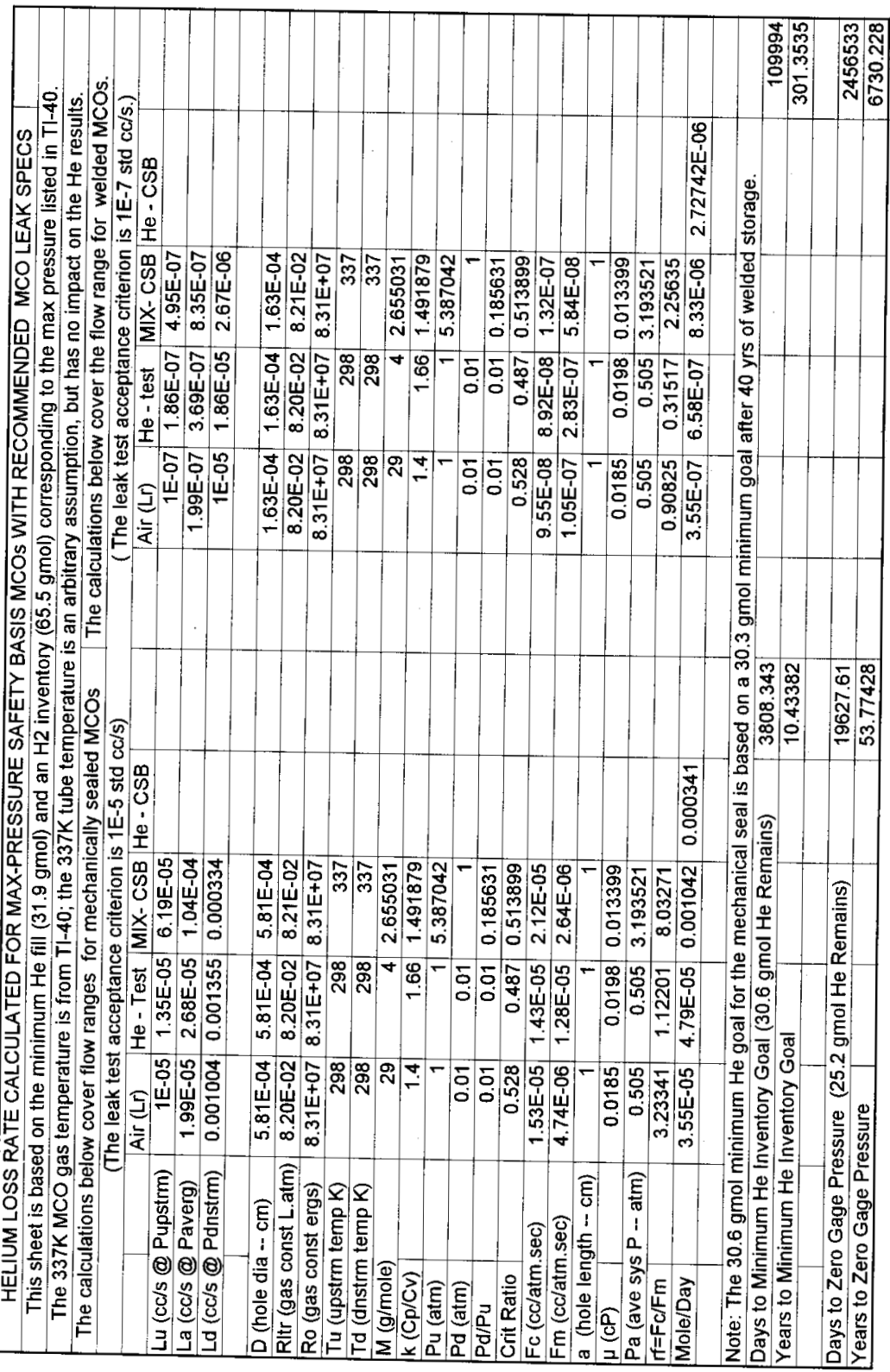




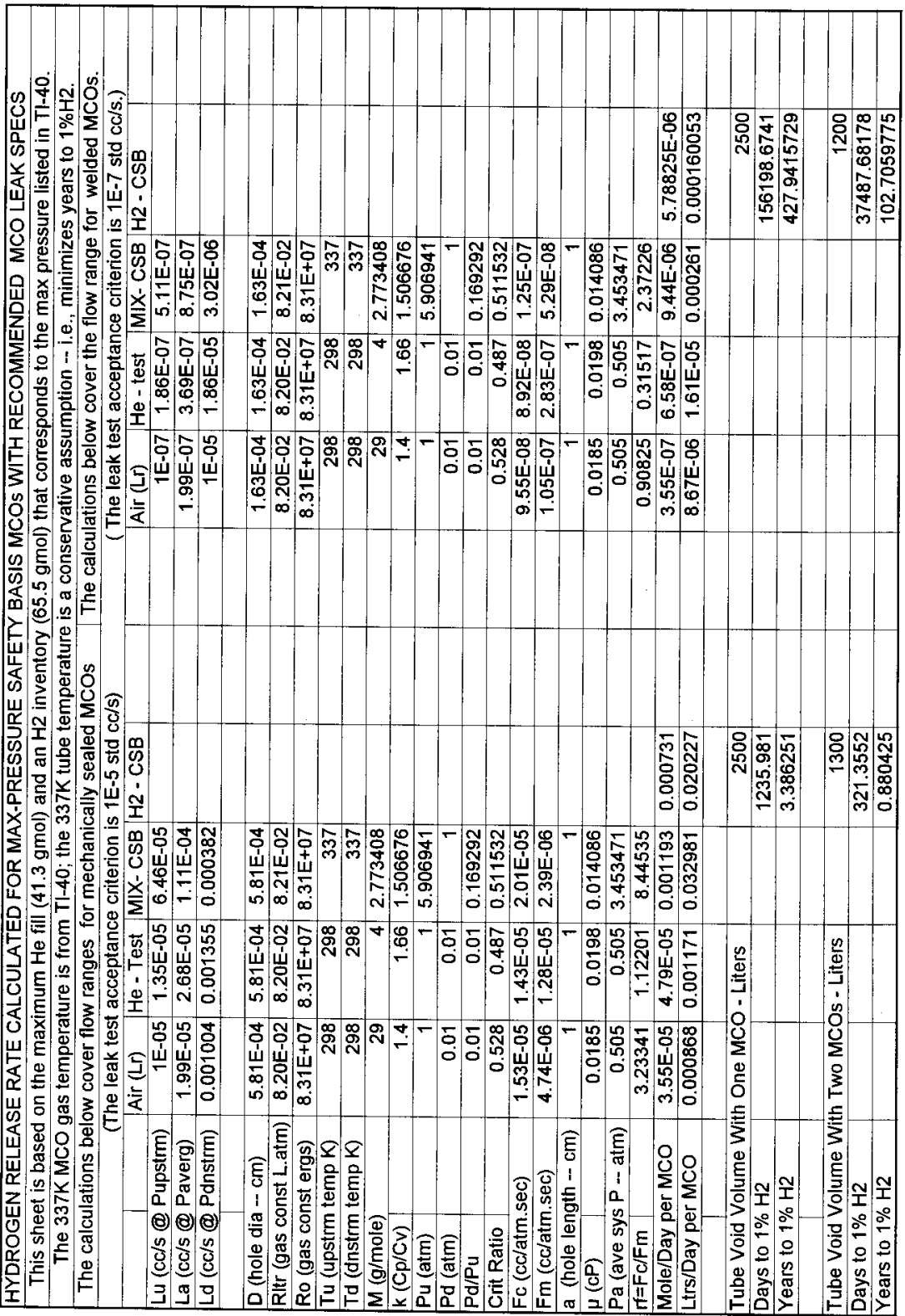




\section{APPENDIX B: THE NFPA 69 EXPLOSION PREVENTION STANDARD}

The stated purpose of NFPA 69 is to prevent explosions in enclosures that contain combustible gases, mists, or dusts. An explosion is defined by the standard as "The bursting or rupture of an enclosure or a container due to the development of internal pressure from a deflagration." A deflagration is defined as "Propagation of a combustion zone at a velocity that is less than the speed of sound in the unreacted medium." Paragraph 1-1.2 of the standard specifically states that it does not apply to devices or systems designed to protect against detonations, which it defines as "Propagation of a combustion zone at a velocity that is greater than the speed of sound in the unreacted medium." It also excludes, among other things, unconfined deflagrations and the design, construction, and installation of deflagration vents.

The standard recognizes two general classes of techniques for preventing explosions. One class is based on combustion prevention while the other is based on preventing or limiting damage from combustion.

Four methods are recognized for 7 imiting or preventing damage from combustion: 1) deflagration suppression, 2) deflagration pressure containment. 3) spark extinguishing, and 4) isolation. Because hydrogen is very easy to ignite over a wide range of hydrogen and oxygen concentrations, and because it would be very difficult to demonstrate that a hydrogen burn could not result in a detonation. as opposed to a deflagration, none of these methods appears to apply (one possible exception would be to demonstrate adequate deflagration pressure containment, based on a limited oxygen concentration - - see section 5.1.2.2.1). This is not to say that the MCO. shipping cask. MCO Hand7ing Machine (MHM) Cask. or storage tube designs wi 71 not require analysis to demonstrate capability to withstand a detonation with no unacceptable consequences. However. if it were necessary to perform such an analysis, it would not be performed to any requirement of NFPA 69.

Two methods are recognized for preventing combustion: 1) oxidant concentration reduction, and 2) combustible concentration reduction.

Chapter 2 of the standard covers application of the oxidant reduction technique. Paragraph 2-7.2 provides the operating limits and instrumentation requirements for systems that will be operated below the Limiting Oxidant Concentration (LOC). See section 5.1.1.1 for additional detai1 regarding the specific operating iimits and instrumentation requirements that are invoked by the standard.

Chapter 3 covers application of the combustible reduction technique. Paragraph 3-3 provides design and operating requirements for systems that will be operated below the Lower Flammable Limit (LFL). Paragraph 3-3.1 requires that the combustible concentration be maintained at or below 25\% of the LFL (i.e. $25 \%$ of 4 vol\% for hydrogen in air $=1$ vol\%). An exception is provided to allow combustible concentrations up to $60 \%$ of the LFL for systems that have the capability to automatically shut off the source of combustible material or otherwise prevent a combustion event (automatic activation of quenching systems, etc.) by means of instrumentation with safety interlocks. 
Fina17y, NFPA 69 addresses situations where it is either impossible or inappropriate to meet any or a11 of the detailed requirements that it invokes. Paragraph 1-1.3 of states that "Nothing in this standard sha 17 be intended to prevent the use of systems, methods, or devices of equivalent or superior quality, strength, fire resistance, effectiveness, durability, and safety over those prescribed by this standard. provided technical documentation is made available to the authority having jurisdiction to demonstrate equivalency and the system, method, or device is approved for the intended purpose." 
HNF-2155 Rev 1

APPENDIX C: ALTERNATE CALCULATIONS 


\section{LOSS OF HYDROGEN FROM CSB TUBES VIA DIFFUSION}

Whereas the calculations and results in section 7.3 are based on dilution of hydrogen by barometrically induced atmospheric breathing alone, the attached alternate calculation is based on loss of hydrogen from the tubes via diffusion alone, with no allowance for any mass flow of gas to or from the tubes. And, whereas the calculations in section 7.3 are based on complete mixing of the air and hydrogen within each tube, this alternate calculation limits that assumption to the void space between the bottom of the tube plug and the upper surface of the top MCO. A.1 other void spaces, including the vent penetrations/lines and the annular space between the bottom of the tube piug and the bottom of each vent penetration, are assumed to be stagnate. As shown on the last page of the attached hand written sheets, the diffusion calculation predicts that, based on the diffusion mechanism alone, the maximum steady state hydrogen concentration will not exceed 0.7 vol\%.

Considering that both mechanisms (breathing and diffusion) are shown to result in maximum steady state hydrogen concentrations that are well below 1 vol\% (0.9 vol\%, based on breathing alone, and 0.7 vol\%. based on diffusion alone) along with the fact that both mechanisms will actually be active at the same time, the overal1 conclusion is that no vented CSB tube will ever even approach I vol\% hydrogen (let alone the 4 vol\% LFL) unless it contains an MCO with a defective seal. 
HNF-2155 Rev 1

ANALYTICAL CALCULATIONS

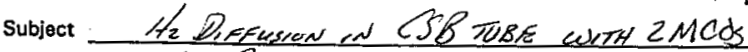

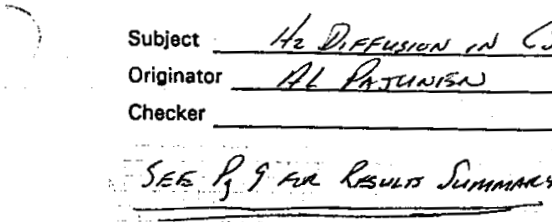

Date

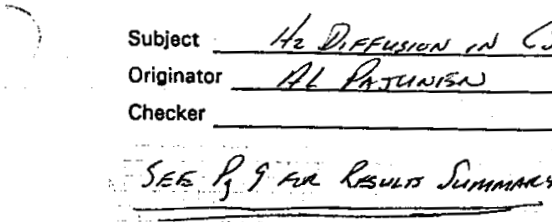

Date

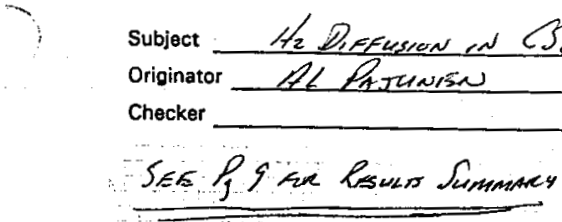

Page 1 of $q$

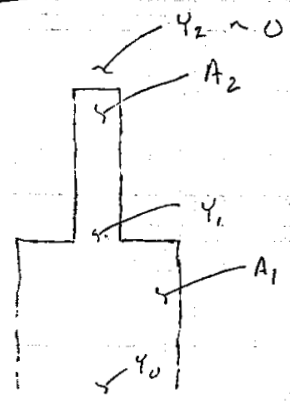

$$
\begin{aligned}
& z_{2}, \\
& z_{1} \quad C=\frac{P}{R T}
\end{aligned}
$$

$N=\frac{\dot{n}}{A_{1}}=\frac{\dot{n}}{A_{2}}$

$z_{0}=0$

$N \frac{S_{M O L}}{S_{A_{1}^{2}-Y_{R}}}=\frac{e D_{A B}}{\left(z_{2}-z_{1}\right)} \operatorname{Ln}\left(\frac{1-y_{2}}{1-y_{1}}\right)$

$\frac{\hat{n}}{A_{2}}=\frac{D_{A B} P}{R T\left(z_{2}-z_{1}\right)} \ln \left(\frac{1-Y_{z}}{1-Y_{1}}\right)$

AND

$$
\frac{\dot{n}}{A_{1}}=\frac{D_{A B} P}{R_{T}\left(z_{1}-z_{0}\right)} \ln \left(\frac{1-Y_{1}}{1-Y_{0}}\right)
$$

Ean $26.5 \mathrm{Fac}$ DHFrusion THRousen a staknant gas (CONSTANT AERA) iN $\omega_{\text {Fith }} \omega_{1 \text { axs }}+$ whesoul (rog)

Tror top stion

$$
\begin{aligned}
& \frac{\dot{n}}{A_{z}}=\frac{D_{A B} \rho}{R_{T}\left(z_{2}-z_{1}\right)} \operatorname{Ln}\left(\frac{y-y_{z}}{1-y_{1}}\right)=\frac{D_{A_{A}} \rho}{R_{T}\left(z_{2}-z_{2}\right)} \operatorname{Ln}\left(\frac{1}{1-y_{1}}\right) \\
& \frac{\dot{n} R T\left(B_{Z}-z_{1}\right)}{A_{2} D_{A B} P}-\operatorname{Ln}\left(1-Y_{1}\right)
\end{aligned}
$$

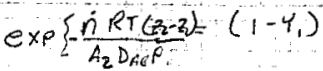

$$
\begin{aligned}
& Y_{1}=1-\exp \left\{-\frac{n R T\left(\varepsilon_{2}-2\right.}{A_{2} D_{\text {AS }} P}\right\}
\end{aligned}
$$

PEr W W 1969,

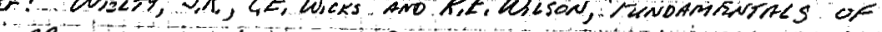

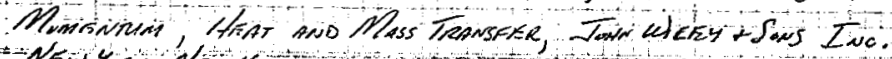

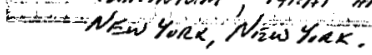

44

BD-6400-060.1 (07/93) 
HNF-2155 Rev 1

ANALYTICAL CALCULATIONS

Page 2 of 9

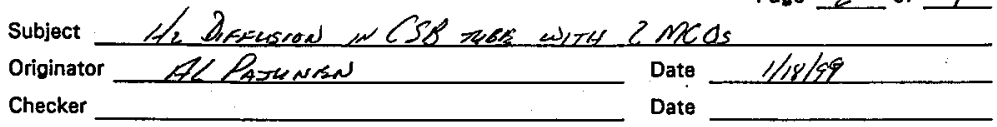

Fur BotTom région:

$$
\begin{aligned}
& \frac{n \operatorname{RT}\left(z,-z_{0}\right)}{A_{1} D_{A B} P}=\ln \left(\frac{1-4_{1}}{1-z_{0}}\right)
\end{aligned}
$$

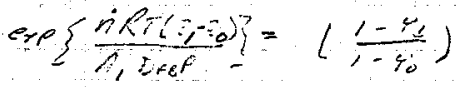

$$
\begin{aligned}
& \left(1-s_{0}\right) \operatorname{Exp}\left\{\frac{\operatorname{DRT}\left(z_{1}-z_{0}\right)}{A_{1} 0_{t} p}\right\}=\left(1-y_{1}\right)
\end{aligned}
$$

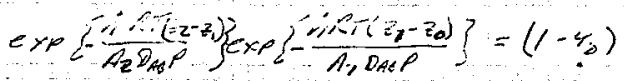

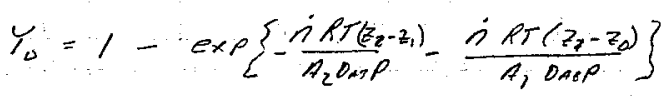

$$
\begin{aligned}
& =1-\exp \left\{-\frac{\dot{R} R T}{D_{A S} P}\left(\frac{\left(z_{L} z_{1}\right)}{A_{2}}+\frac{\left(z_{L}-z_{0}\right)}{A_{1}}\right)\right\} \\
& A_{2}=2 \times \frac{\pi}{4}(3 / 4 \times 2.54)^{2}=5.7 \mathrm{~cm}^{2} \\
& \left(z_{2}-\dot{z}_{1}\right)=24 \times 2.54=61 \mathrm{~cm}
\end{aligned}
$$

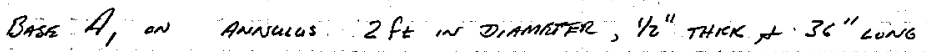

$$
\begin{aligned}
& A_{1} \pi(2.12 \cdot 2.54)(1 / 2 \cdot 2.54)=213 \mathrm{~cm}^{2} \\
& \left(z_{1}-z_{0}\right)=36 \times 2.54=91.5 \mathrm{~cm}
\end{aligned}
$$

$\because \quad$ Fewm Pran's 5 ED AS 3-222, TABur 3-294

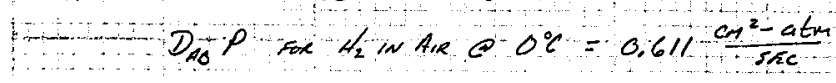

45

BD-6400-060.1 (07/93) 
HNF-2155 Rev 1

ANALYTICAL CALCULATIONS

Subiect Hz DefFuston in CSA ruse curnt 2 MCOS

Originator

Date

Checker

Page 3 of 9

Date

Trmeroers,

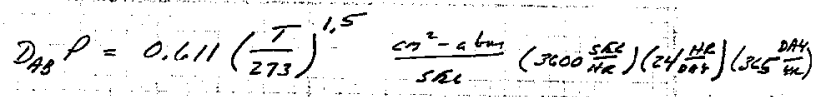

$\ldots, \cdots=1.93 \times 10^{\circ}\left(\frac{T}{273}\right)^{\circ 5} \frac{\mathrm{cm}^{2}-46 m}{4 x}$

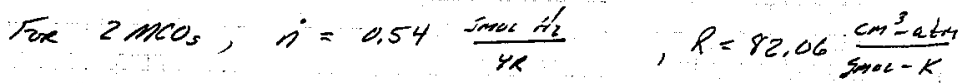

At $T=337 K, \quad D_{A B} P=2,45 \times 10^{2} \frac{\cos ^{2}-a m_{m}}{4 R}$

$$
\begin{aligned}
& Y_{1}=1-\exp \left\{-\frac{\dot{\theta} P_{T} T}{A_{2} D_{A B} P}-Z_{2}-z_{j}\right\}
\end{aligned}
$$

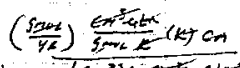

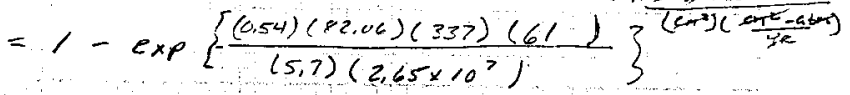

$$
\begin{aligned}
& =1-0,944 \\
& =0.006
\end{aligned}
$$

$$
\begin{aligned}
& Y_{0}=1-\exp \left\{-\frac{j R T}{\partial_{n} P}\left(\frac{\left(z_{2}-z_{1}\right)}{A_{2}}+\frac{\left(z_{1}-z_{0}\right)}{A_{1}}\right)\right\} \\
& =1-e_{x p}\left\{-\frac{(0.54)(82.06)(331)}{\left(2.65 \times 10^{7}\right)}\left(\frac{-6.1}{5.7}+\frac{91.5}{243}\right)\right\} \\
& =1-0.9938 \\
& =0.00 \mathrm{~h}
\end{aligned}
$$

46

8D-6400-060.1 (07/93) 
- HF -2155 Rev 1 $1 \ldots$

ANALYTICAL CALCULATIONS

Page 4 of 2

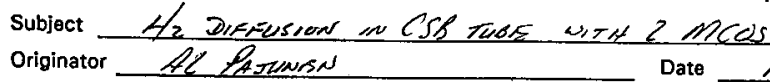

Date

Checker

Date

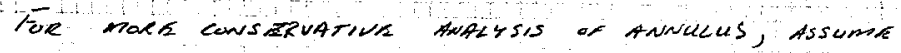
ZONAL OF STAGNANT CUNCFNTRATTONS -

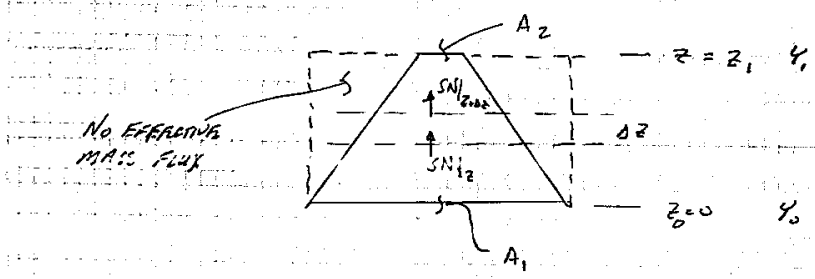

CAlANGR en GROSS SECTION ARKA IS

$$
\begin{aligned}
S & =A_{2}-\frac{\left(A_{2}-A_{1}\right)}{z_{1}} z \quad \operatorname{lE} \quad \frac{\left(A_{2}-A_{1}\right)}{z_{1}}=\alpha \\
& =A_{2}-\alpha z
\end{aligned}
$$

AT SS,

$$
\begin{gathered}
\lim _{\Delta z \rightarrow 0} \frac{S N / z+\Delta z-S N / z=0}{\Delta z} \\
\frac{d}{d z}(S N)=0 \\
S N=C, A \text { coss } \\
\therefore A_{2}\left(\frac{\dot{n}}{A_{2}}\right)=C \\
\therefore \quad \dot{n}=C \\
\therefore \quad \therefore=\frac{n}{S}=\frac{n}{A_{z}-\alpha z}
\end{gathered}
$$

a $z=0, S=A_{2}$

$$
N=\frac{\dot{\theta}}{A_{2}}
$$

BD-6400-060.1 (07/93)

47 
HNF-2155 Rev 1

ANALYTICAL CALCULATIONS

Page 5 of 9

Subjact Hz Diffeusian in CSB rase wTH 2 NKO Originator Al Peruerses

Checker

Dato 1/18/95

Date

$$
\begin{aligned}
N=-\frac{C D_{A B}}{1-y} \frac{d y}{d z}=\frac{\dot{r}}{A_{2}-\alpha z} \\
=\frac{C D_{A B}}{n} \int_{Y_{0}}^{y} \frac{d y}{1-y}=\int_{0}^{z_{1}} \frac{d z}{A_{2}-\alpha z}
\end{aligned}
$$

Equ 26-3 sein Whaty, Wicks +Whesow (1965)

$$
\begin{aligned}
& -\frac{C D_{A B}}{n}\left(-\left.\operatorname{Ln}(1-y)\right|_{\%} ^{4}\right)=-\frac{1}{\alpha}\left(\left.\ln \left(A_{2}-\alpha z\right)\right|_{0} ^{Z_{1}}\right) \\
& \frac{C D_{A B}}{n} \ln \left(\frac{1-Y_{1}}{1-y_{0}}\right)=-\frac{1}{\alpha} \operatorname{Ln}\left(\frac{A_{2}-\alpha Z_{1}}{A_{2}}\right) \\
& \alpha z_{1}=\frac{\left(A_{2}-A_{1}\right)}{z_{1}} z_{1}=\left(A_{2}-A_{1}\right)
\end{aligned}
$$

$$
\begin{aligned}
& \ln \left(\frac{1-\varphi_{1}}{1-\eta_{2}}\right)=-\frac{\dot{\eta}}{C D_{A B} \alpha} \operatorname{Ln}\left(\frac{A_{1}}{A_{2}}\right) \\
& C=\frac{P R T}{P D_{T}}
\end{aligned}
$$

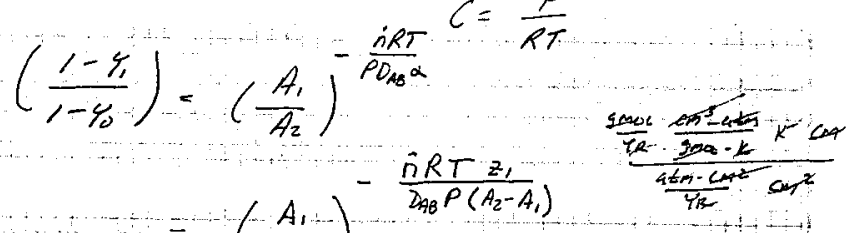

$$
\begin{aligned}
& =\left(\frac{A_{1}}{A_{2}}\right)
\end{aligned}
$$

48

BD-6400-060.1(07/93) 
HNF-2155 Rev 1

ANALYTICAL CALCULATIONS

Page 6 of -9

Subject H/2 DIFFUSION IN CSB TUEE with 2 MCOS

Originator Al Plogueneas

Checker Date Clis/gr

Date

Socurite rue $\%_{0}$

$$
\psi_{0}=1-\left(1-Y_{1}\right)\left(\frac{A_{1}}{A_{2}}\right)^{\frac{n R T z_{1}}{D_{A B} P\left(A_{2}-A_{1}\right)}}
$$

Feum $P_{5} 3, \cdots Y,=0.003$, USE SHMETRY TO MAKE

SOLUTION APPLCABLA, i.e.

$$
\begin{aligned}
& A_{1}=\frac{243}{2}=1 \mathrm{crs} \mathrm{cm}^{2} . \quad z_{1}=11,5 \mathrm{~cm} \\
& A_{2}=\frac{5.7}{2}=2.85 \mathrm{~cm}^{2} \quad R=82.06 \frac{\mathrm{atm}-\mathrm{cm}^{3}}{\frac{5.404}{\mathrm{k}} \mathrm{K}}
\end{aligned}
$$

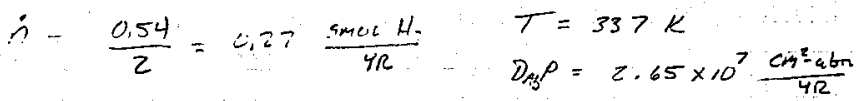

$$
\begin{aligned}
& Y_{0}=1-(1-.006)\left(\frac{121.5}{2.85}\right) \\
& \left(\frac{(.27)(82.04)(337)(91.5)}{\left(2.05 \times 10^{7}\right)(2.85-121.5)}\right) \\
& =1-(1-, 006)(42,43)^{-2.17 \times 10^{-4}} \\
& =1-0.9932 \\
& 0,0068 \\
& \text { COMPARED T0 } 0,0062 \text { 45Sumins } \\
& \text { CONSTANT AREA }
\end{aligned}
$$

49

BD-6400-060.1 (07/93) 
HNF-2155 Rev 1

ANALYTICAL CALCULATIONS

Page 7 of 9

Subject

Ha Defesien in CSP reBE wrt 2 MCOS

Originator

Date

$1 / 18 / 55$

Checker

Date

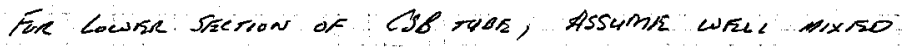

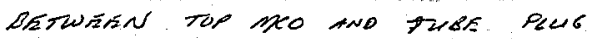

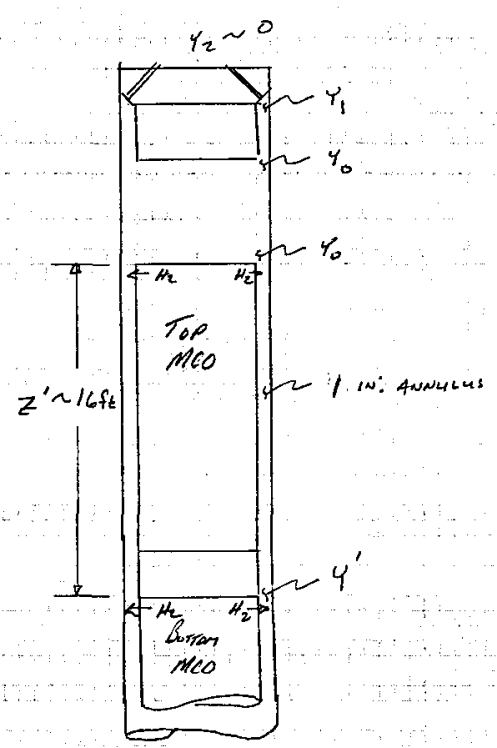

$$
\begin{gathered}
N=\frac{\dot{n}}{A^{\prime}}=\frac{C D_{A B}}{z^{\prime}} \ln \left(\frac{1-y_{0}}{1-y^{\prime}}\right) \\
\frac{\dot{n}}{A !}=\frac{P D_{A B}}{R T z^{\prime}} \ln \left(\frac{1-y_{0}}{1-y^{\prime}}\right) \\
\ln \left(\frac{1-y_{0}}{1-y^{\prime}}\right)=\frac{\dot{n} P T z^{\prime}}{A^{\prime} P A_{A B}}
\end{gathered}
$$

50

BD-6400-060.1 \{07/93\} 
INF - 2155 Rev 1

ANALYTICAL CALCULATIONS

Page $\mathscr{Z}$ of $y$

Subject tie Defeusean an CSB TuBe with 2 MOS

Originator

Al Paruarisa

Date

Checker

Date

$$
\begin{aligned}
& \left(1-\psi_{0}\right) \exp \left\{-\frac{n R T z^{\prime}}{A^{\prime} D_{A} P}\right\}=1-Y^{\prime} \\
& Y^{\prime}=1-\left(1-\psi_{0}\right) \exp \left\{-\frac{i R T Z^{\prime}}{A^{\prime} D_{\text {se }} P}\right\}
\end{aligned}
$$

Fore DHS STeTsON

$$
\begin{aligned}
& \dot{n}=\frac{0.54}{Z}=0.27 \frac{\mathrm{smoc} / \mathrm{t}}{4 \mathrm{~K}} . \quad D_{A B} P=2.65 \times 10^{7} \frac{\mathrm{cm}^{2}-4 \mathrm{tm}}{\mathrm{qR}} \\
& T=337 \mathrm{~K} \\
& A^{\prime}=\pi \cdot(24 \times 2.54)(1 \times 2.54)=486 \mathrm{~cm}^{2} R=82.06 \frac{\mathrm{abm}-\mathrm{cm}^{3}}{5 \text { mae }-\mathrm{t}} \\
& z^{\prime}=16 \times 12 \times 2.54=48 \% \mathrm{~cm} \quad \%=0.0068 \text { Feu is } 6 \\
& y^{\prime}=1-(1-0.0068) \exp \left\{-\frac{(0.27)(82,06)(337) 488}{(986)\left(2.65 \times 10^{7}\right)}\right\} \\
& =1-(1-40068) 0.4957 \\
& =0.0071
\end{aligned}
$$

51

BD-6400-060.1 (07/93) 
HNF-2155 Rev 1

ANALYTICAL CALCULATIONS

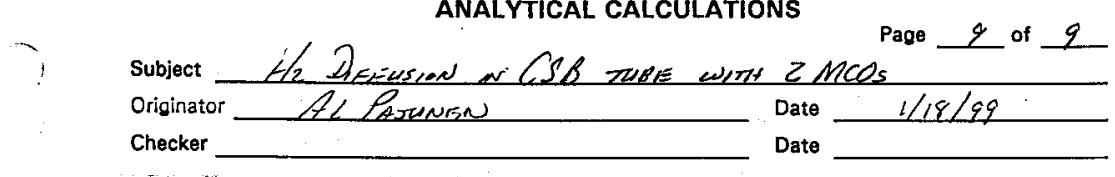

Sampied of lescuers

(Most cunstavartis mastas)

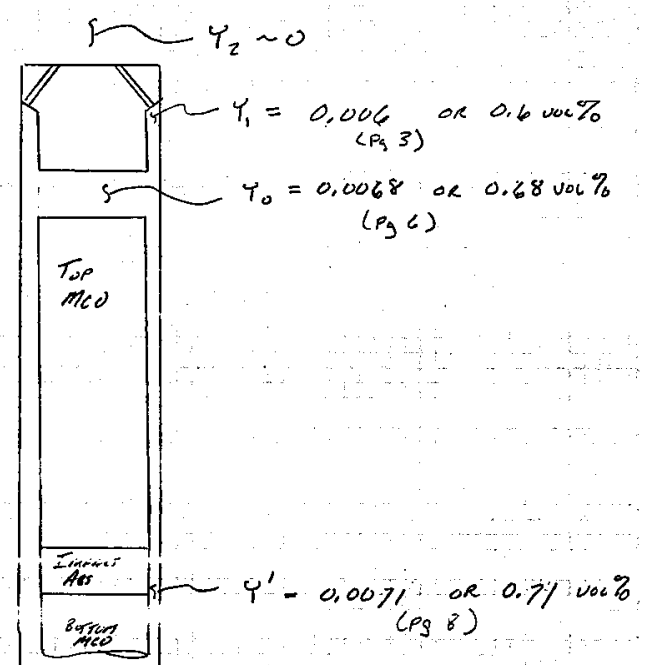

52

BD-6400-060.1 (07/93) 
HNF-2155 Rev 1

APPENDIX D: INDEPENDENT REVIEW 


\section{REVIEW CHECKLIST}

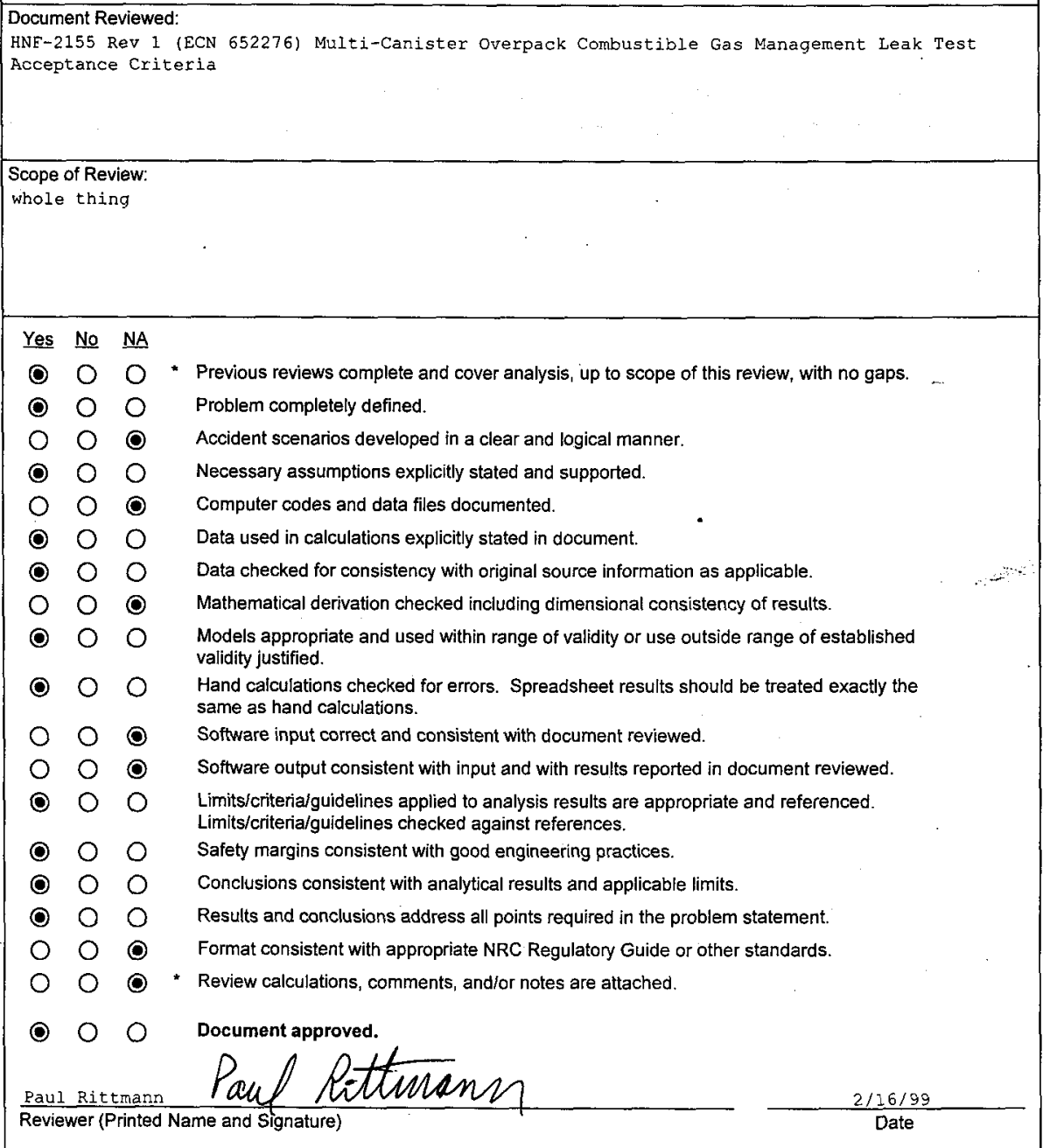

"Any calculations, comments, or notes generated as part of this review should be signed, dated and attached to this checklist. Such material should be labeled and recorded in such a manner as to be intelligible to a technically qualified third party. 
HNF-2155 Rev 1

\section{APPENDIX E: REFERENCES}

ANSI N14.5, 1987, American National Standard For Radioactive Materia7s -leakage tests on packages for shipment. American National Standards Institute, Inc., New York, NY.

ANSI N14.5, 1997, American National Standard For Radioactive Materials -leakage tests on packages for shipment -- Draft J, American National Standards Institute. Inc. New York, NY.

NFPA 69. 1997. Standard on Explosion Prevention Systems, National Fire Protection Association.

NRC, 1978, Control of Combustible Gas Concentrations in Containment Following a Loss-of-Coolant Accident. NRC Regulatory Guide 1.7. U.S. Nuclear Regulatory Commission, Washington, D.C.

HNF-1719, Draft Rev D, Canister Storage Bui7ding Process Technical Manua 7. COGEMA Engineering Corporation. Richland. WA, 1998.

HNF-SD-SNF-TI-040, Rev 3. MCO Internal Gas Composition and Pressure During Interim Storage. DE\&S Hanford Inc. . Richland. WA, 1997.

HNF-SD-SNF-RD-007. SNF Canister Storage Building and Hot Conditioning System Standards/Requirements Identification Document, DE\&S Hanford Inc., Richland. WA, 1997.

HNF-SD-OCD-001. Draft Rev. 4. Spent Nuclear Fue7 Project Product Specification. DE\&S Hanford Inc., Richland, WA, 1997.

HNF-S-0426, Rev. 5. Performance Specification for the Spent Nuclear Fuel Multi-Canister Overpack. DE\&S Hanford Inc., Richland, WA, 1997.

HNF-SD-TP-SARP-017. Rev. 1 Safety Analysis Report for Packaging (Onsite) Multi-canister Overpack Cask, DE\&S Hanford Inc., Richland, WA, 1997.

PNNL-11471. Hanford Site C7imatologica7 Data Summary 1996 With Historical Data. Pacific Northwest National Laboratory. (1996).

WHC-EP-0651, Barometric Pressure Variations, Westinghouse Hanford Company, Richland WA, 1993.

WHC-SD-SNF-TRP-018. Test Report For Multiple Canister Overpack Mechanical Closure Prototype Testing, Rust Federal Services of Hanford, Inc., Richland, WA, 1996.

Scott Specialty Gases. Scott Specialty Gases catalog. Scott Environmental Technology Inc. Plumsteadvi11e. PA, 1985.

Welty, James R., Charles E. Wicks, and, Robert E. Wilson, Fundamenta7s of Momentum. Heat and Mass Transfer, John Wi ley \& Sons, Inc. New York, NY, 1969. 


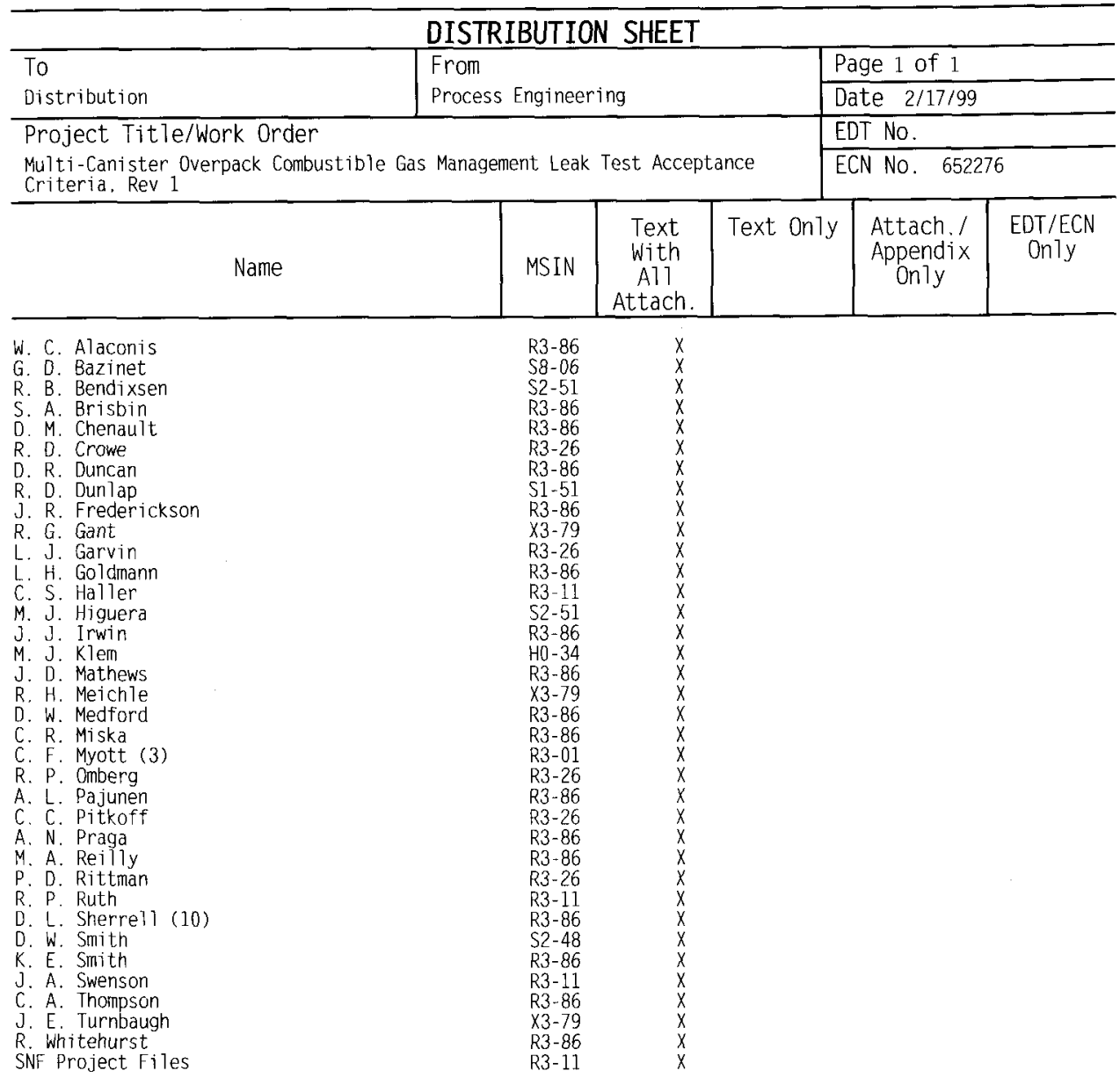

